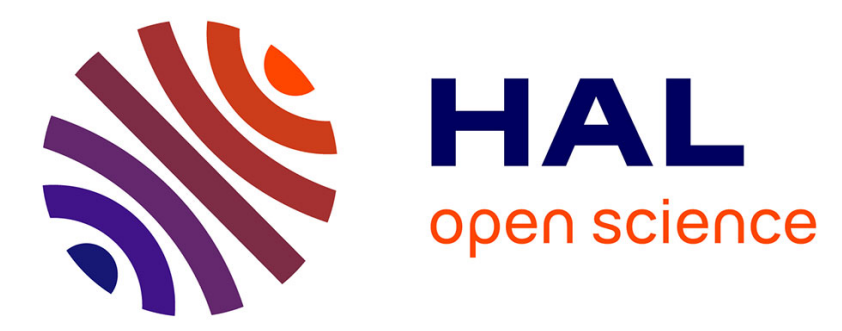

\title{
Influence of controlled depth abrasive water jet milling on the fatigue behavior of carbon/epoxy composites
}

Akshay Hejjaji, Redouane Zitoune, Lotfi Toubal, Laurent Crouzeix, Francis Collombet

\section{- To cite this version:}

Akshay Hejjaji, Redouane Zitoune, Lotfi Toubal, Laurent Crouzeix, Francis Collombet. Influence of controlled depth abrasive water jet milling on the fatigue behavior of carbon/epoxy composites. Composites Part A: Applied Science and Manufacturing, 2019, 121, pp.397-410. 10.1016/j.compositesa.2019.03.045 . hal-02134037

\section{HAL Id: hal-02134037 \\ https://hal.science/hal-02134037}

Submitted on 22 Oct 2021

HAL is a multi-disciplinary open access archive for the deposit and dissemination of scientific research documents, whether they are published or not. The documents may come from teaching and research institutions in France or abroad, or from public or private research centers.
L'archive ouverte pluridisciplinaire HAL, est destinée au dépôt et à la diffusion de documents scientifiques de niveau recherche, publiés ou non, émanant des établissements d'enseignement et de recherche français ou étrangers, des laboratoires publics ou privés.

\section{다)(1) $\$$}

Distributed under a Creative Commons Attribution - NonCommerciall 4.0 International 


\title{
Influence of controlled depth abrasive water jet milling on the fatigue behavior of carbon/epoxy composites
}

\author{
Akshay Hejjaji ${ }^{1}$, Redouane Zitoune ${ }^{1}$, Lotfi Toubal ${ }^{2}$, Laurent Crouzeix $^{1}$, Francis Collombet $^{1}$ \\ ${ }^{1}$ Institut Clément Ader, UMR CNRS 5312, University of Toulouse, Toulouse, France \\ ${ }^{2}$ Université du Québec à Trois-Rivières, Trois-Rivières, Canada
}

\begin{abstract}
Conventional milling during aircraft structural composite repair encourages defect generation and distortion, causing hindrance in milling depth control and thereby adversely affecting their mechanical behavior. Abrasive water jet (AWJ) milling can be an alternative to avoid these problems. In this study, carbon/epoxy laminates are milled using AWJ and machined surfaces are characterized at micro (surface texture) and macro (damage size) scales. Defects in the form of craters, ridges-valleys and broken fibers are identified and quantified. A new parameter "crater volume $\left(\mathrm{C}_{\mathrm{v}}\right)$ " is proposed to quantify and qualify the machining quality in terms of induced damage. This introduces a novel approach to characterize the machined surface without ignoring the machining damage. Milled specimens with different damage levels are subjected to tensile and tension-tension fatigue tests instrumented with thermography and acoustic-emission transducers. Machined specimens with high $\mathrm{C}_{\mathrm{v}}$ exhibited inferior fatigue behavior and X-ray tomography revealed that crack/fracture initiation occurred from the crater edges.
\end{abstract}

Keywords: Polymer-matrix composites (PMCs); Abrasive water jet milling; Surface properties; Fatigue behavior. 


\section{Introduction}

Carbon fiber reinforced plastics (CFRPs) are class of advanced materials offering several advantages such as: a very high strength-to-weight ratio / high modulus-to-weight ratio and corrosion resistance. These attributes make them a popular choice of engineering material in aerospace, marine, robotics, construction, transportation, sporting goods, and defense applications. Usage of composites in any of these applications requires a specific shape, size, load bearing capacity, geometrical and damage tolerance. To obtain these attributes they undergo series of processing operations starting from mold curing to machining. Though composites are manufactured to near net shape; secondary machining operations like trimming, milling, grinding and hole making are always necessary to produce the final functional component [1-3]. Apart from machining during manufacturing phase, machining is also required for repairing the damages caused during service in the later life cycle of the structural composite parts especially during aircraft maintenance $[4,5]$.

It is a well-known fact that the conventional machining of CFRP composites is an arduous task because of their highly abrasive and heterogeneous nature. The presence of distinct phases of fiber reinforcements and a polymer matrix both having highly varying mechanical, thermal and physical properties makes machining of composites a complex task where cutting tool interaction is not simple like in the case of machining of metals. Apart from heterogeneity, the complexity is also due the mechanism of material removal, which is strongly derived by relative angle between the direction of the cutting speed and the fiber orientation [1-3]. Several research studies on conventional milling of CFRPs presents many kinds of damages like delamination, fiber pull-outs, matrix recession, inter-laminar cracks, distortion and thermal degradation whose nature, size and position primarily depend on machining parameters and fiber orientation with respect to the cutting direction [1-3,6-9]. Conventional machining of CFRP composites leads to excessive and premature tool wear due to the brittle and abrasive nature of the carbon fibers. In fact, the rate of the wear is accelerated when dry machining is conducted; this also leads to also high machining temperatures. In addition, the low thermal conductivity of matrix and the high machining temperatures leads to thermal degradation of the machined surface (charred/brunt matrix) [6,10]. Apart from extensive damage caused to the work piece, another major disadvantage of conventional machining is generation of dangerous levels of carbon fiber dust (particulate emissions) that affects the environment and is extremely harmful to the operator $[10,11]$. All these limitations led to rapid development of machining CFRPs by non-conventional 
processes like abrasive water jet, laser, and electrical discharge machining $[1,10]$. However, several studies report numerous defects like delamination, matrix cracking, matrix degradation and matrix burnout, matrix recession, thermal damage and hazardous fumes during laser machining [7,12]. Also, damages like high thermal degradation, recast layer, fiber swelling and delamination along spark channel was reported during electrical discharge machining [13]. In comparison, defects like broken fibers, craters, fiber-matrix debonding, grit embedment and striations were reported during AWJ machining (both trimming and controlled depth milling) of composites [14-17]. It is important to note that AWJ machining process does not induce any thermal defects and studies have demonstrated that AWJ machining with optimal parameters leads to delamination free trimming and milling of CFRPs, making it an interesting and favorable alternative for controlled depth surface milling of composites [1,14-16,18].

The AWJ machining is a well-established non-conventional machining process which has proved to be effective in machining a wide range of materials including composites $[1,19]$. Numerous studies have demonstrated effective approaches for machining CFRPs with AWJ and meanwhile preserving the material integrity by using optimal machining parameters $[17,18,20]$. In comparison with conventional machining, AWJ machining imposes minimal forces on the work piece, does not require any specific tooling, and does not produce any heat affected zones (no thermal defects). In addition, machining mechanism is independent of fiber orientation and in terms of impact on environment and also abrasive water jet process is considered to be least harmful to the operator in comparison with the conventional and laser machining process. During AWJ machining the jet stream safely carries away most of the harmful carbon dust along with it and no toxic fumes are involved thereby minimizing the health hazard endured by the operators. Typically, AWJ machining is used mostly for trimming. However, in the last decade, it has been used for controlled depth milling of metals [21-24], besides some studies have also demonstrated the feasibility of this process for composites [1,15,16,24-26]. Studies on AWJ milling of CFRP composites by Hejjaji et al. $[15,16]$ prove that AWJ milling can produce industrially acceptable machining quality by careful optimization of process parameters to reduce surface anomalies and machining induced defects. Material removal rate is an important parameter for an industry to accept the process for economic reasons. However, it is also seen from the same work that, the jet pressure is the major factor deciding the MRR, and other factors like traverse speed, scan step and standoff distance have negligible influence $[15,16]$. At the same time, it is also observed that jet pressure is also the main factor influencing the surface roughness and crater volume. Hence, 
it is clear that high MRR can be achieved by using high jet pressure for milling, at the cost of machining quality. Surface milling is a crucial procedure while repairing structural composite parts like fuselage in aircrafts. The repair is accomplished by removing the damaged zones of the structural component and patching it with new material [4,5]. The damaged plies from the affected structures are usually removed by surface milling or scarfing process by conventional machining techniques. Often scarfing process is performed manually; it involves highly skilled labor and long maintenance schedules making the repair process economically unreasonable. The repair procedure is highly intricate and is controlled by stringent guidelines by the aviation authorities and maintenance and repair organizations (MRO) providers. This repair procedure requires grounding of the aircraft for several days and highly skilled labor. This is a huge overhead and economic burden to the aviation companies. This means that, an agile repair procedure needs to be in place for all the economic reasons. Additionally, the quality and the strength of the repair depend on the surface texture and defect free milling. The stringent norms and guidelines enforced by aviation authorities add up to the difficulties of the already complicated repair procedure. Considering the drawbacks of conventional milling, AWJ milling can be an alternative solution to overcome the problems experienced, particularly for repairing composites in aerospace sector. Unfortunately, the research data available for milling of composites by AWJ process is inadequate to successfully industrialize the process. Also, there is no research data available on the machining quality obtained and its impact on mechanical behavior of composites. These research gaps lead to the main objective of this study.

Every machining technique has its own physics of material removal and that mechanism will impact the properties of the newly generated surface. In AWJ machining the material removal is due to micro erosion caused by solid particle impact. The bombardment of abrasive particles on the work piece surface causes high contact stresses leading to micro fracture, chipping and lateral crack formation $[19,27]$. In CFRPs this micro-mechanism of material removal is evident by presence of broken fibers and micro craters on the machined surface. This material response is determined by the brittle properties of the carbon fibers. A combination of micro-machining and the brittle fracture of the fibers are observed when the abrasive laden jet stream is impinging on the composite work piece [14-16,28-30]. Also, variations in flow patterns due to machine constrains like water pressure fluctuations and nozzle vibration will change the erosion conditions and resulting surface properties entirely depend on the milling parameters. For example, studies on milling CFRP by Hejjaji et al. $[15,16]$ show that increasing jet traverse speed 
will increase surface roughness but decrease surface waviness as the effect of water pressure fluctuations will be minimum at higher traverse speeds. It is clear that due to the material removal mechanism there is a probability of significant work piece surface degradation. Many researchers attribute the main cause of deviation in mechanical behavior of composites from the original bulk material to the machining quality [8,16,38,20,31-37]. For instance, Haddad et al. [8] have shown that, the compressive failure stress of specimens trimmed by AWJ process is $15 \%$ superior to those trimmed by conventional process (Abrasive diamond disk) which is attributed to difference in surface properties and defects induced by the different techniques of machining. Studies on impact of machining quality on mechanical behavior of composites have linked surface properties (Arithmetic average surface roughness $-\mathbf{R}_{a}$ ) to the mechanical behavior [8,20,31,32,36,37] . Industrially, arithmetic criterion " $\mathrm{R}_{\mathrm{a}}$ " is one of the important parameter used to quantify and qualify the machined surface. However, when this parameter $\left(R_{a}\right)$ is considered for composite materials, contradictory results have been observed. Ideally good machining quality is qualified by low value of $\mathrm{R}_{\mathrm{a}}$ which should lead to better mechanical performance, but the results in the literature are quite ambiguous. For example, the tensile tests conducted on unidirectional (UD) glass fibers/epoxy samples have shown that the tensile strength increases with the increase of the average surface roughness $\left(\mathrm{R}_{\mathrm{a}}\right)$ [36]. On the contrary, the results of compressive mechanical tests conducted by Squires et al. [37] on UD specimens machined by diamond saw have shown that the failure stress decreases with the increase of the surface roughness. Similarly, in work of Haddad et al. [8] when AWJ trimmed multidirectional (MD) CFRP was subjected to compressive loading, it was observed that a reduction in $\mathrm{R}_{\mathrm{a}}$ led to increase in the compressive strength. However, when trimming is conducted by conventional machining (Abrasive diamond cutter) process the evolution of the compressive strength in function of the roughness $\mathrm{R}_{\mathrm{a}}$ is random, i.e.; specimen with higher $R_{a}$ value exhibited higher compressive strength in few cases. Also, investigations on compressive strength of FRPs conducted by Ramulu et al. [20] show that the surface roughness of the machined (trimming) surface does not have a clear impact on the compressive strength. However, it was explained that the major factor for the compressive strength reduction is the extent of delamination caused by mechanisms of material removal. Hence, it is clear that, average surface roughness, $R_{a}$ developed initially for machining metallic materials cannot be confidently used for the characterization of the machined surface of composite materials. Also, qualification of machining quality based on surface roughness criterion can be misleading as acknowledged by several researchers [16,36]. Hence, there is need of a criterion specific to composite materials to qualify the surface and machining quality in order 
to accurately link the machining quality to the mechanical behavior. Hence, we can conclude that machining will degrade the mechanical properties of the composites and it is necessary to precisely quantify the machining quality to predict the mechanical behavior of the machined composites. This leads to the objective of this study where the impact of AWJ surface milling of CFRP on mechanical behavior is investigated to ascertain the usability of the process.

The scope of the present work focuses on the quantification of milling damage induced by the AWJ process on multi-directional (MD) CFRP specimens and its influence on the mechanical behavior during static (tensile tests for the maximum failure load) and fatigue (tension-tension tests for the endurance limit) loading. It is important to mention that the machining parameters have been selected in order to generate different levels of surface quality (different forms and size of damage). In addition, the machined surfaces are characterized at micro (surface texture) and macro (damage size) scales using 3D optical topography and scanning electron microscopy (SEM). As explained earlier, traditional characterization of surface quality based on the standardized parameters such as " $\mathrm{R}_{\mathrm{a}}$ " perhaps be inappropriate for the machined surfaces of composite materials. Hence, a new parameter named "crater volume $\left(\mathrm{C}_{\mathrm{v}}\right)$ " which characterizes the surface quality is proposed and correlated to the mechanical behavior. This parameter $\left(\mathrm{C}_{\mathrm{v}}\right)$ is calculated by analyzing surface topologies. After the surface characterization, the machined specimens are multi-instrumented by extensometer for the strain measurement, infra-red camera for the measurement of the dissipated temperature and acoustic emission transducer for the damage detection and tension-tension fatigue tests are conducted. In addition, the specimens are subjected to X-ray tomography imaging after loading at different stress levels to understand the damage scenario and progression (failure initiation and fracture propagation) with respect to the machining induced defects.

\section{Materials and Methods}

\subsection{Composite material}

Carbon fiber reinforced plastic (CFRP) laminates were prepared using unidirectional (UD) pre-pregs supplied by Hexcel Composites Company and referenced as HexplyT700-M21. This pre-preg is used to manufacture primary and secondary parts of some aircrafts like the A380 and A400M. A multidirectional(MD) laminate of size $300 \mathrm{~mm}$ x $300 \mathrm{~mm}$ with 22 and 24 plies and a stacking sequence $\left[90^{\circ} / 90^{\circ} / 90^{\circ} /-45^{\circ} / 0^{\circ} / 45^{\circ} / 90^{\circ} /-45^{\circ} / 90^{\circ} / 45^{\circ} / 90^{\circ}\right] \mathrm{s}$ and $\left[90^{\circ} / 90^{\circ} / 90^{\circ} / 90^{\circ} /-\right.$ 
$\left.45^{\circ} / 0^{\circ} / 45^{\circ} / 90^{\circ} / 45^{\circ} / 90^{\circ} / 45^{\circ} / 90^{\circ}\right] \mathrm{s}$ respectively, was used for the tests. The normal stacking sequence for utilization is $\left[90^{\circ} / 90^{\circ} /-45^{\circ} / 0^{\circ} / 45^{\circ} / 90^{\circ} /-45^{\circ} / 90^{\circ} / 45^{\circ} / 90^{\circ}\right] \mathrm{s}$ with 20 plies, but here the extra $90^{\circ}$ plies were added at the ends to obtain a final stacking sequence of $\left[90^{\circ} / 90^{\circ} /\right.$ $45^{\circ} / 0^{\circ} / 45^{\circ} / 90^{\circ} / 45^{\circ} / 90^{\circ} / 45^{\circ} / 90^{\circ}$ ]s (20 plies) after milling in order to get the same comparable stacking sequence for all specimens. The laminate stacks were prepared in a controlled atmosphere (white room) and compaction was carried out for 12 hours using a vacuum pump. A mold for the laminate was prepared and placed in a vacuum bag and evacuated to -0.7 bar. Curing process was then conducted at $180^{\circ} \mathrm{C}$ for 120 min during which the pressure was maintained at 7 bar in an autoclave (as recommended by Hexcel Composites). The temperature rise rate in the autoclave was $5^{\circ} \mathrm{C} / \mathrm{min}$. The nominal fiber volume fraction was around $59 \%$ and average ply thickness was $0.26 \mathrm{~mm}$ with this process of manufacturing. From each laminate, 4 coupons of size $145 \mathrm{~mm}$ x $145 \mathrm{~mm}$ were cut using the AWJ cutting process. Then each coupon was milled by AWJ process with different machining parameters to obtain specimens with variations in surface quality and damage levels.

\subsection{Abrasive water jet milling}

The milling experiments were performed on the AWJ Machine manufactured by "Flow International Corporation”. The abrasive used was garnet sand available under the marketing name "Bengal Bay Garnet" originating from coasts of southern India in Bay of Bengal and supplied by "Opta Minerals". In order to generate specimens with different levels of damage some machining parameters were kept constant for all experiments (cf. Table1) and parameters: jet pressure (P), jet traverse speed (S), scan step (SS) and standoff distance (SD) were varied at different levels for milling (cf. Table 2). The parameter selection was based on our previous work $[15,16]$.

\begin{tabular}{|c|c|c|c|}
\hline Parameters & Value & Parameters & Value \\
\hline Focusing tube diameter & $1.016 \mathrm{~mm}$ & Type of abrasive & Garnet sand \\
\hline Focusing tube length & $76 \mathrm{~cm}$ & Abrasive flow Rate & $0.34 \mathrm{~kg} / \mathrm{min}$ \\
\hline Nozzle orifice diameter & $0.3302 \mathrm{~mm}$ & Abrasive grit size & $\# 120(125 \mu \mathrm{m})$ \\
\hline Abrasive flow & Venturi effect & Abrasive hardness & $7.5 \mathrm{Mohs}$ \\
\hline
\end{tabular}

Table 1. AWJ milling parameters fixed for all specimens. 
The raster scan pattern was considered for the milling path strategy, and direction of milling was maintained parallel to $90^{\circ}$ fiber orientation (cf. Fig. 1a). The direction parallel to $90^{\circ}$ fiber orientation is considered longitudinal direction and direction perpendicular to $90^{\circ}$ fiber orientation is considered as transverse direction. From each $300 \mathrm{~mm}$ x $300 \mathrm{~mm}$ laminate, 4 coupons of size $145 \mathrm{~mm}$ x $145 \mathrm{~mm}$ were cut using AWJ. The CFRP specimens were securely clamped on wood plank to avoid displacement during milling. The milling was performed on both sides of the laminate to avoid errors that may arise during mechanical tests due to warping and asymmetry (cf. Fig. 1b). Each coupon was milled using different machining parameters to get variety of surfaces and damage levels. The selection of machining parameters to obtain exact milled depth and variety of damage were based on our previous work where the calculations were performed using full factorial experiments performed on similar CFRP laminates [15]. Two groups of specimens were used for the studies, 'Group A' where 1 ply on each side of laminate with 22 plies was milled and 'Group B' where 2 plies were milled on each side of the laminate with 24 plies in order to finally obtain 20 plies laminate of thickness $4.7 \pm 0.2 \mathrm{~mm}$ (cf. Fig. $1 \mathrm{~b}$ ). The nomenclature, AWJ milling parameters used and characteristic damage of the specimens are presented in Table 2.

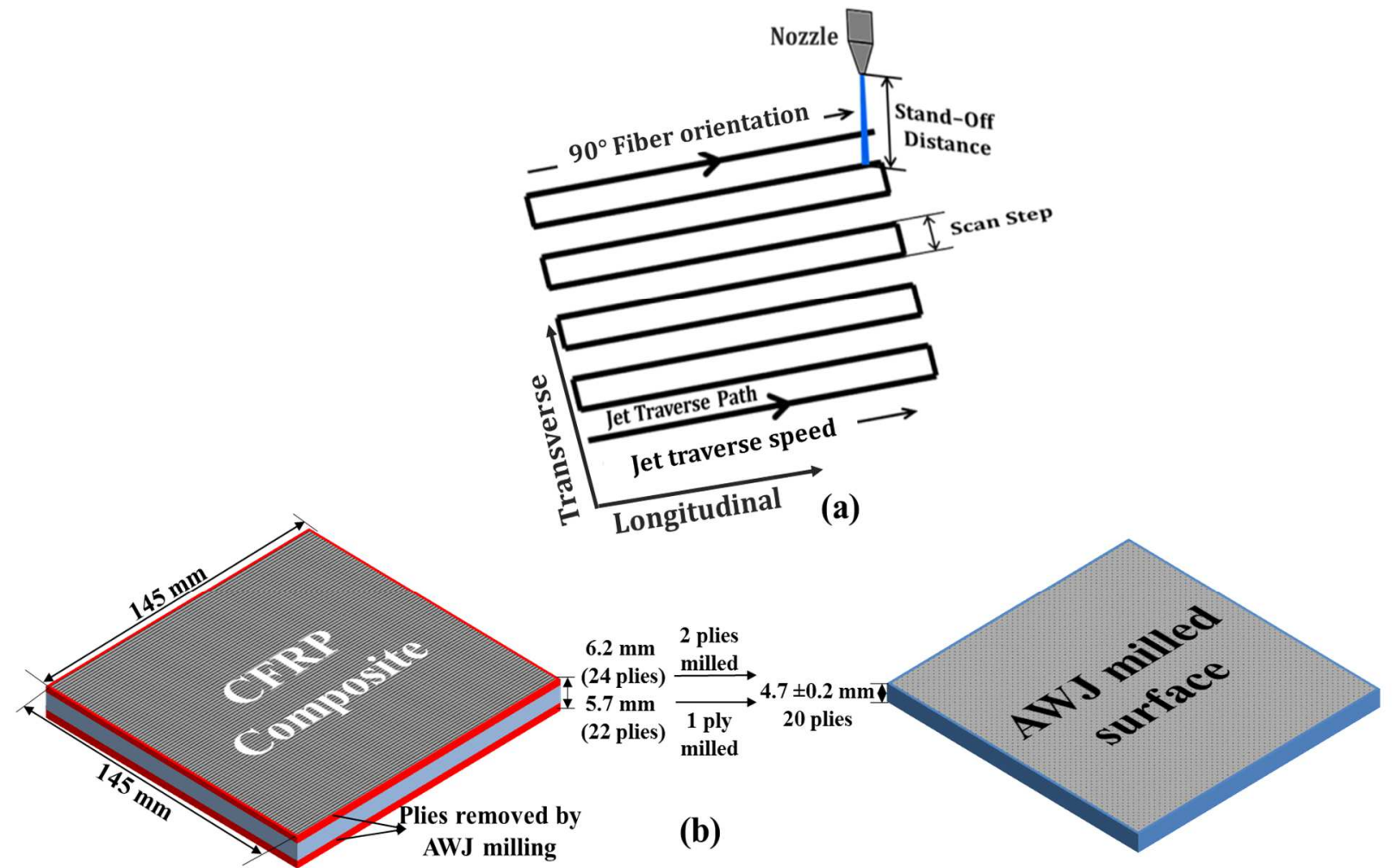

Fig. 1. AWJ milling of CFRP laminates (a) Schematic view of the AWJ milling pattern with respect to the fiber orientation. (b) Geometry of the milled feature (Face milling) 


\begin{tabular}{|c|c|c|c|c|c|c|}
\hline Coupon & $\begin{array}{c}\text { Characteristic } \\
\text { damage }\end{array}$ & $\begin{array}{c}\text { Jet pressure } \\
\mathbf{P}, \text { (MPa) }\end{array}$ & $\begin{array}{c}\text { Traverse Speed } \\
\mathbf{S},(\mathrm{m} / \mathrm{min})\end{array}$ & $\begin{array}{l}\text { Scan step } \\
\text { SS, (mm) }\end{array}$ & $\begin{array}{l}\text { Standoff } \\
\text { SD, (mm) }\end{array}$ & $\begin{array}{c}\text { Plies milled } \\
\text { (Milling } \\
\text { depth, mm) }\end{array}$ \\
\hline A1 & $\begin{array}{l}\text { Macro craters } \\
\text { (Poor quality) }\end{array}$ & 80 & 12 & 0.5 & 50 & \multirow{4}{*}{$\begin{array}{c}1 \\
(0.26 \pm 0.08 \\
\mathrm{mm})\end{array}$} \\
\hline $\mathbf{A} 2$ & Valleys & 80 & 8 & 1.5 & 50 & \\
\hline A3 & $\begin{array}{c}\text { Macro craters } \\
\text { (Intermediate } \\
\text { quality) }\end{array}$ & 80 & 10 & 1.5 & 100 & \\
\hline A4 & Good quality & 100 & 10 & 1.0 & 100 & \\
\hline B1 & $\begin{array}{l}\text { Macro craters } \\
\text { (Poor quality) }\end{array}$ & 80 & 4 & 1.5 & 100 & \multirow{4}{*}{$\begin{array}{c}2 \\
(0.52 \pm 0.08 \\
\mathrm{mm})\end{array}$} \\
\hline B2 & Valleys & 120 & 12 & 1.5 & 50 & \\
\hline B3 & $\begin{array}{c}\text { Macro craters } \\
\text { (Intermediate } \\
\text { quality) }\end{array}$ & 140 & 12 & 1.5 & 100 & \\
\hline B4 & Good quality & 140 & 12 & 1.5 & 150 & \\
\hline
\end{tabular}

Table 2. Specimen nomenclature, the main characteristic damage and the AWJ milling parameters used to obtain the mechanical tests specimens.

\subsection{Metrology and characterization methods}

The milled surfaces were subjected to microscopy and profilometric characterization. Scanning electron microscope (SEM) was at used different magnification levels to observe the milled surface and to identify the various kinds of damage. 3D Topography of the milled surface was obtained using a non-contact extended field confocal microscope, "AltiSurf520". These topographical measurements were made on a representative area of $10 \mathrm{~mm}$ (longitudinal) x $8 \mathrm{~mm}$ (Transverse) with a spatial scanning resolution of $8 \mu \mathrm{m}$. Surface profile parameters like 2D roughness $\left(\mathrm{R}_{\mathrm{a}}\right)$ and waviness $\left(\mathrm{W}_{\mathrm{a}}\right)$ and $3 \mathrm{D}$ average surface height $\left(\mathrm{S}_{\mathrm{a}}\right)$ were extracted from the topography using “MountainsMap ${ }^{\circledR}$ " Software developed by "Digitalsurf”. A Gaussian filter (cut-off $=0.8 \mathrm{~mm}$ ) was applied to isolate roughness and waviness. 2D and 3D surface parameters 
were extracted with respect to ISO 4287 and ISO 25178 standards. The topographies were analyzed to quantify the size and volume of craters for different machining parameters using hole volume measurement tool (Least squares plane method) available in the MountainsMap ${ }^{\circledR}$ Software. This measurement of crater volume provides a novel approach to characterize the machined surface quality without ignoring the machining damage.

\subsection{Mechanical tests and instrumentation}

The influence of damage induced by the AWJ milling process on the mechanical behavior is studied by conducting static tensile and tension-tension fatigue tests. These tests have been carried out on specimens with 4 different levels of machining quality. The specimen size and test methods were followed according to the ASTM standards D3039 and D3479 for static tensile and tension-tension fatigue tests respectively. The test coupons were cut from the $145 \mathrm{~mm} \times 145$ $\mathrm{mm}$ milled and characterized specimens using AWJ to the size of $145 \mathrm{~mm}$ x $14 \mathrm{~mm}$ (cf. Fig. 2). The test coupons were tabbed with $1.5 \mathrm{~mm}$ thick aluminum tabs having a bevel angle of $45^{\circ}$. The static tensile tests were performed on MTS landmark 370.10 servo-hydraulic load frame instrumented with $100 \mathrm{kN}$ load cell and an extensometer, in which specimens were held in the test frame using hydraulic grips. The load was applied at a rate of $1 \mathrm{~mm} / \mathrm{min}$. Finally, to obtain the ultimate failure stress the actual area of cross section was measured using the X-Ray tomography images so as to obtain a more realistic cross sectional area instead of using a rectangular approximation which would lead to erroneous results. For each kind of specimen, 2 static tensile tests were performed and the average of tensile strength values obtained from these 2 tests was considered for all calculations.

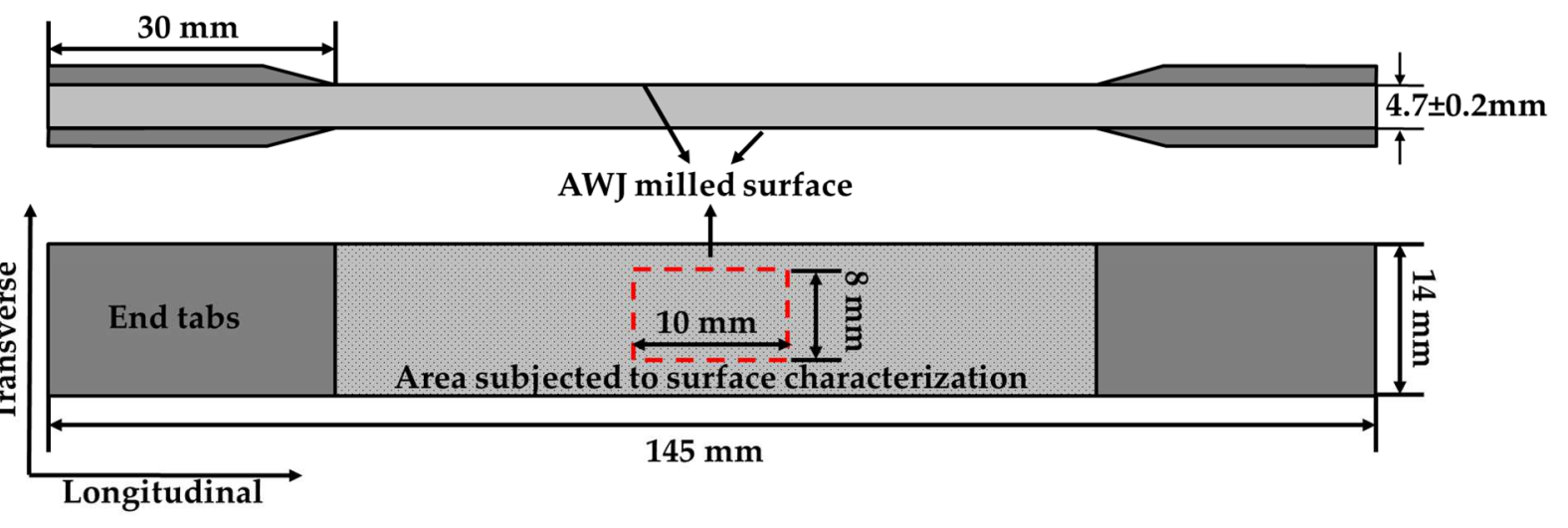

Fig. 2. Test specimen geometry showing dimensions and machined area subjected to surface characterization. 


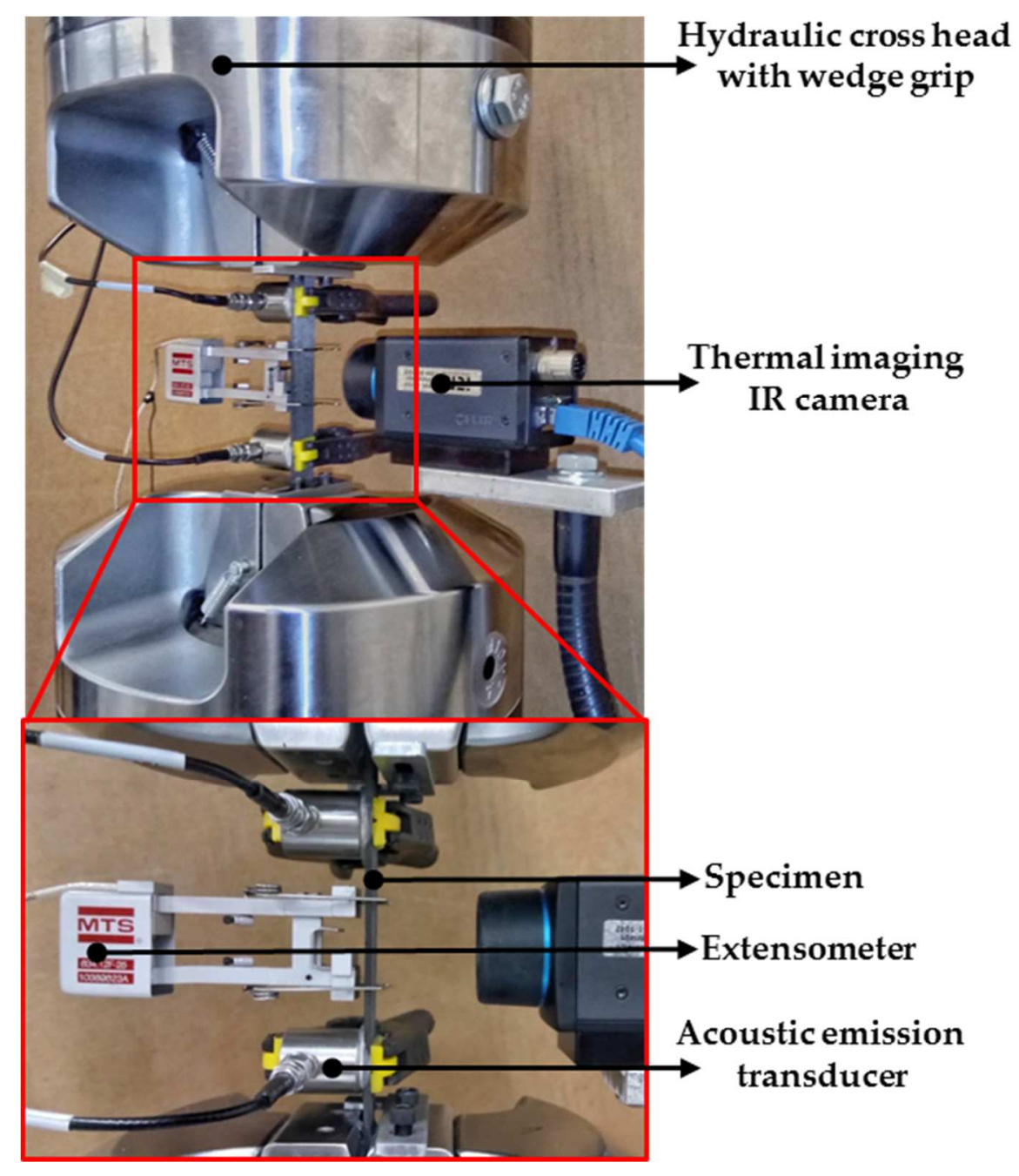

Fig. 3. Setup showing instrumentation used for tension-tension fatigue tests.

The tension-tension fatigue tests were conducted on the same machine used for the static tests instrumented with $100 \mathrm{kN}$ load cell. In addition, multi-instrumentation including; extensometer, infrared thermal camera and acoustic emission transducers (cf. Fig. 3) were used. The ultimate tensile load values $\left(\mathrm{F}_{\mathrm{uts}}=\mathrm{Load}\right.$ at $\sigma_{\mathrm{uts}}$ ) obtained from the static tests were used to design the fatigue tests. The specimens were subjected to 10,000 sinusoidal cycles of tensiletensile loads (stress ratio $\left(\mathrm{F}_{\max } / \mathrm{F}_{\min }\right) \mathrm{R}$ of 0.1 and at room temperature) at $15 \% \mathrm{~F}_{\mathrm{uts}}, 30 \% \mathrm{~F}_{\mathrm{uts}}, 40 \%$ $\mathrm{F}_{\mathrm{uts}}, 50 \% \mathrm{Futs}_{\mathrm{uts}}, 60 \% \mathrm{~F}_{\mathrm{uts}}, 70 \% \mathrm{~F}_{\mathrm{uts}}$ and $80 \% \mathrm{~F}_{\mathrm{uts}}$ at $10 \mathrm{~Hz}$. Each load block was separated with dwell time of 10 minutes to let the specimens return to its initial/room temperature. The tension-tension fatigue test loading protocol is shown in the Fig. 4. For each kind of specimen 3 tests were conducted to obtain a good repeatability ( 8 specimens $\mathrm{x} 3$ tests each $=$ Total 24 tests).

A Flir A35 infrared thermal camera having thermal resolution $<50 \mathrm{mK}$ and operating range of $-25^{\circ} \mathrm{C}$ to $135^{\circ} \mathrm{C}$ was used to record the temperature dissipated due to the fatigue loading 
on the specimen surface. The image resolution and emissivity was set to $320 \times 256$ pixels and 0.99 respectively. The thermo-graphic data was analyzed to estimate the fatigue limit of the specimens using temperature stabilization method [8,39-43]. Usually, the endurance limit is obtained by Whöler curves (stress vs. cycles). However, fatigue limit can also be obtained from the temperature stabilization method by interpolation of two intersecting straight lines of different slopes that fits the stabilization temperature when plotted against the corresponding stress level [8,39-43]. This method is based on the fact that a part of energy required to start the damage propagation is irreversibly transformed into heat and hence, any deformation and damage in the specimen is followed by increase in temperature.

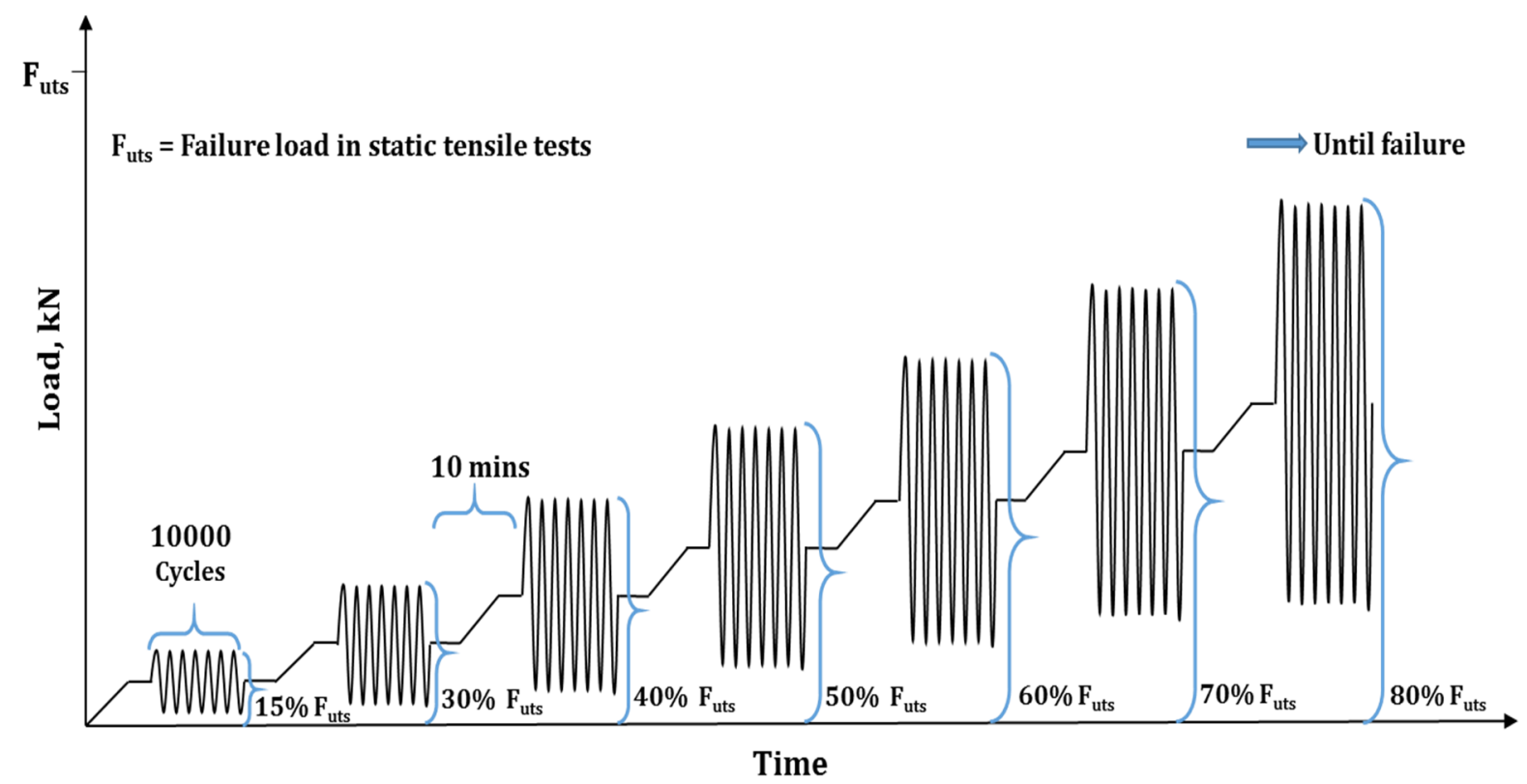

Fig. 4. Tension-tension fatigue test loading protocol with $\mathrm{R}=0.1$ and Frequency $=10 \mathrm{~Hz}$ at room temperature.

\subsection{Postmortem analysis of fatigue damage evolution}

The failure evolution of the specimens under fatigue loading was investigated by conducting X-ray computed tomography analysis on specimens subjected to 10,000 sinusoidal cycles of tension-tension loads (stress ratio $\left(\mathrm{F}_{\max } / \mathrm{F}_{\min }\right) \mathrm{R}$ of 0.1 , frequency of $10 \mathrm{~Hz}$ at room temperature) at $25 \% \mathrm{Futs}_{\mathrm{uts}}, 50 \% \mathrm{~F}_{\mathrm{uts}}$ and $80 \% \mathrm{~F}_{\mathrm{uts}}$. The X-Ray tomography allows performing a non-destructive postmortem analysis of damage evolution in specimens in between blocks of loading cycles. EasyTom $130 \mathrm{X}$-ray tomography machine was used which had an X-ray source voltage and current set to $130 \mathrm{kV}$ and $300 \mathrm{~mA}$, respectively. The resolution of image acquisition was $21 \mu \mathrm{m}$ (Voxel size). 


\section{Results and discussions}

\subsection{Machined surface and damage}

The machined surfaces of the laminates were observed using SEM to identify various kinds of induced damages. The typical forms of damages included micro and macro craters, broken and bare fibers, fiber-matrix debonding, ridge-valleys and abrasive particle embedment (cf. Fig. 5). The classification of micro and macro craters was solely based on the size of the craters (diameter). In fact, the differentiation in the size of these craters was determined by the mechanism of material removal, i.e. interaction between abrasive laden waterjet and the workpiece. Crater sites formed due to the high velocity bombardment of single abrasive particles are termed as micro craters owing to their microscopic size. It was observed from SEM analysis that diameter of these microscopic craters (formed due to single abrasive particle impact) ranged between of $90 \mu \mathrm{m}$ and $200 \mu \mathrm{m}$. It is to be noted that, the abrasive used for the experiments was garnet sand of 120 mesh size which corresponds to a diameter of $125 \mu \mathrm{m}$ and hence the craters created were close to this diameter range. Therefore, $200 \mu \mathrm{m}$ was taken as a threshold to differentiate micro craters from macro craters. However, for the macro caters, the size varied between $200 \mu \mathrm{m}$ and $2 \mathrm{~mm}$. The occurrence of these macro craters was attributed to minor fluctuations in jet pressure, abrasive flow, variability in composite laminate workpiece (porosity, fiber warping, in-plane kinking of fibers) and waterjet nozzle oscillations. Micro craters were present in all the samples irrespective of machining parameters used and were randomly scattered all across the machined surface. However, macro craters appeared only in certain samples and were completely absent in samples machined with high standoff distance owing to the inferior effect of jet pressure fluctuations as standoff distance increased. Also, Macro craters appeared at periodic intervals which may be considered to be in synchronization with the fluctuations in jet pressure or with variability in composite laminate workpiece. Nevertheless, at this stage of the study the mechanism of periodic formation of macro craters is not clearly understood and it requires further investigation. Another predominant damage observed was ridges and valleys. The valleys were deep channels/groves occurring on the jet traverse pathway when the scan step was greater than the interacting jet diameter. When the scan step is greater than the jet diameter in interaction with the workpiece material, less or no material is removed in-between two adjacent jet traverse pathways due to skipping a thin section of jet-workpiece interaction between the paths leading to formation of ridges. 

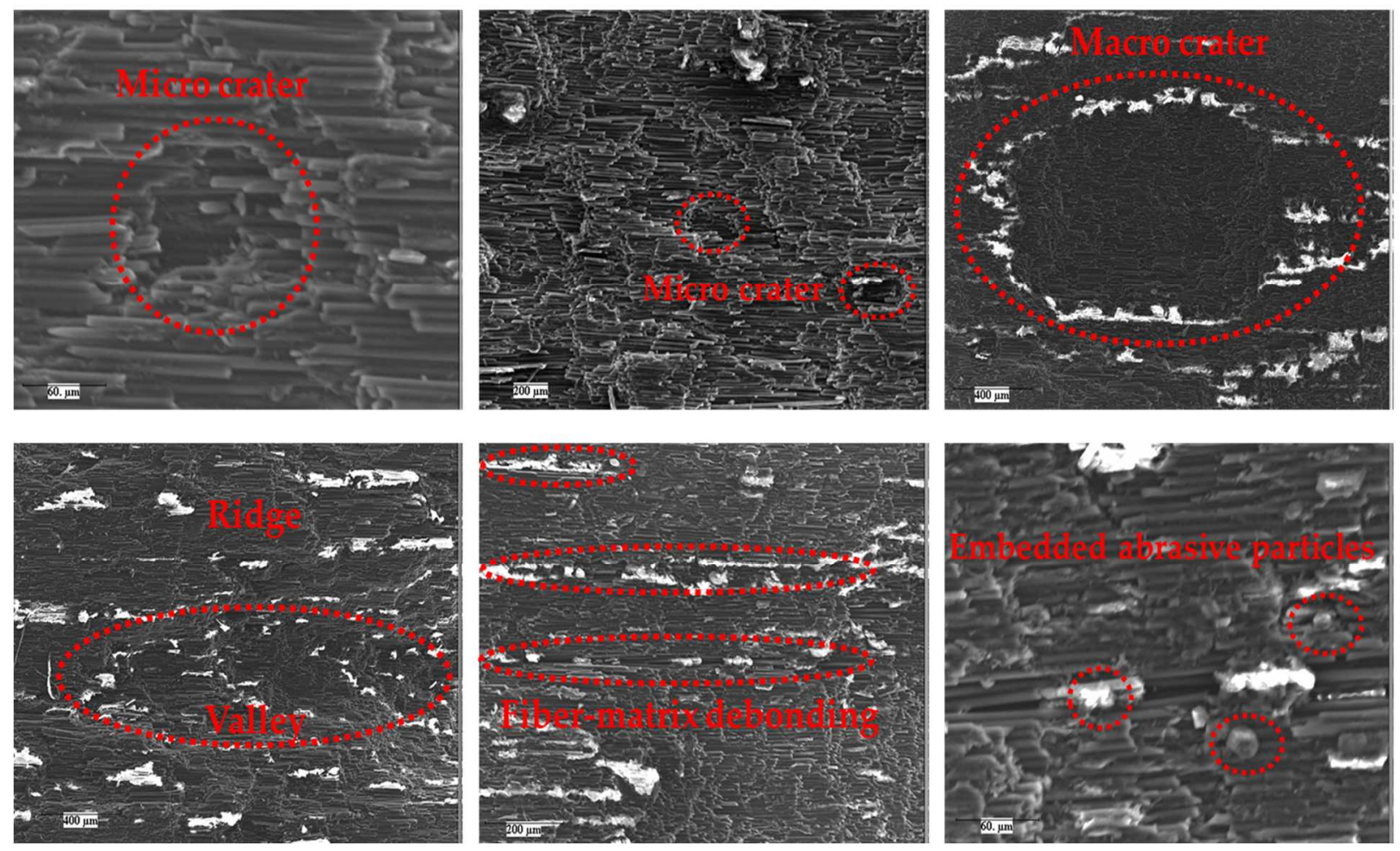

Fig. 5. SEM images showing different kinds of damages in AWJ milled laminates.

The machined surfaces of the laminates were characterized using 2D and 3D surface parameters. The parameters chosen for $2 \mathrm{D}$ characterization were $\mathrm{R}_{\mathrm{a}}$ and $\mathrm{W}_{\mathrm{a}}$ in both longitudinal and transverse directions. The Fig. 6 shows the $\mathrm{R}_{\mathrm{a}}$ and $\mathrm{W}_{\mathrm{a}}$ values of the machined specimens. It can be seen that there is a very low variation in $R_{a}-L$ (values lay between 7-11 $\mu \mathrm{m}$ ). However, high $\mathrm{R}_{\mathrm{a}}-\mathrm{T}$ values are observed in specimens having ridge-valley damage. Also, the $\mathrm{W}_{\mathrm{a}}$ values indicate the presence of the macro craters, i.e. higher the $\mathrm{W}_{\mathrm{a}}$ (Both longitudinal and transverse directions) more is the presence of macro craters. In addition, high $\mathrm{W}_{\mathrm{a}}-\mathrm{T}$ indicates presence of ridges and valleys. It can be observed that $\mathrm{R}_{\mathrm{a}}$ and $\mathrm{W}_{\mathrm{a}}$ fail to characterize the complete machined surface including the damages. Hence, to characterize the machined surface along with damage a comprehensive parameter is calculated by performing topography analysis. The topographies of the machined specimens along with the various kinds of damages are presented in the Fig. 7. These surface topographies are analyzed using hole volume measurement tool (Least squares plane method) available in the MountainsMap ${ }^{\circledR}$ software to obtain the new comprehensive quality parameter crater volume, " $\mathrm{C}_{\mathrm{v}}$ ". The $\mathrm{C}_{\mathrm{v}}$ measurements were made on a representative surface (more than 80 times the jet-workpiece interaction area) of the machined specimen. In addition, the measured surface was located in the middle of the specimens subjected to the mechanical loading (area where a future fracture zone is suspected during mechanical testing) (cf. Fig. 2). 


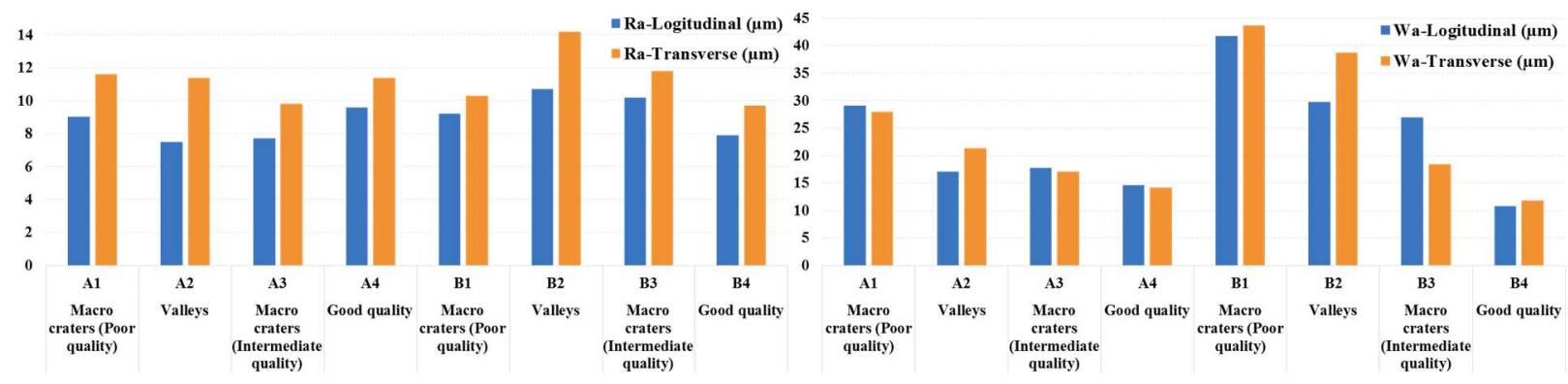

Fig. 6. 2D Surface characterization $\left(\mathrm{R}_{\mathrm{a}}\right.$ and $\left.\mathrm{W}_{\mathrm{a}}\right)$ of milled specimens along longitudinal (L) and transverse $(\mathrm{T})$ directions

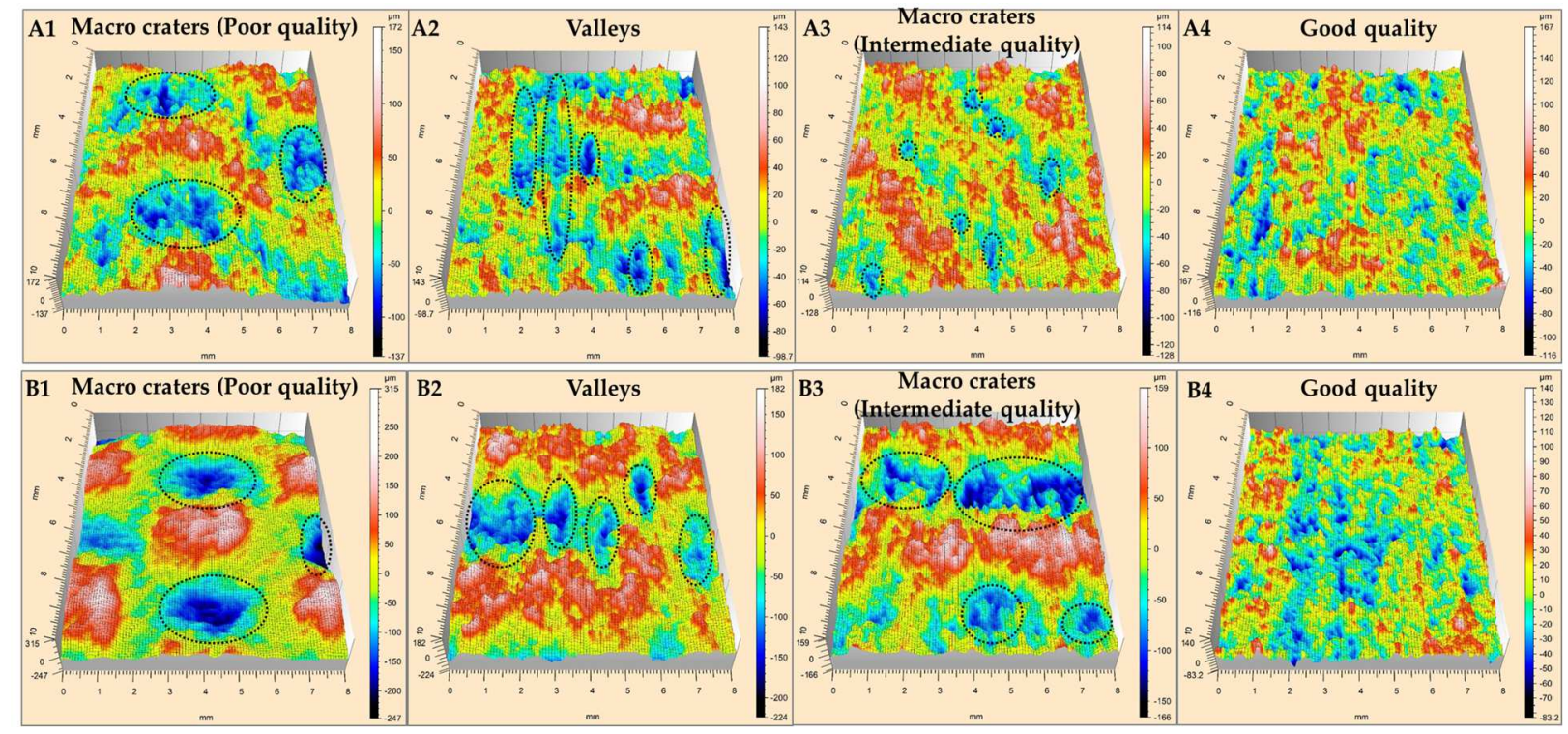

Fig. 7. Surface topography of the milled specimens. A1-A4 1 ply milled and B1-B4 2 plies milled.

The 3D surface parameters $S_{a}$ and $C_{v}$ of the machined specimens are shown in the Fig. 8a. It can be seen that these parameters provide an insight into the level of overall damage unlike 2D parameters. A good quality specimen is characterized by low $S_{a}$ and $C_{v}(A 4$ and $B 4)$. If we observe the $S_{a}$ values of the specimens A2, A3 and A4 we can notice that there is no much variation, even though they have different levels of machining induced damage. As $S_{a}$ is an arithmetic mean height of the surface, the values may even out in some instances leading to flawed quantification of the damage. In comparison, crater volume is the total volume of the recessed material under the mean plane of the surface expressed as volume per unit area. It includes the volume of all the defects viz. craters, voids and valleys generated on the machined 
surface as seen from the schematic in Fig. 8 b. Hence, we see that $C_{V}$ indicates the damage levels in real sense. Therefore, in this study, $\mathrm{C}_{\mathrm{v}}$ is used as a comprehensive surface quality and damage indicator to qualify the machined surface.

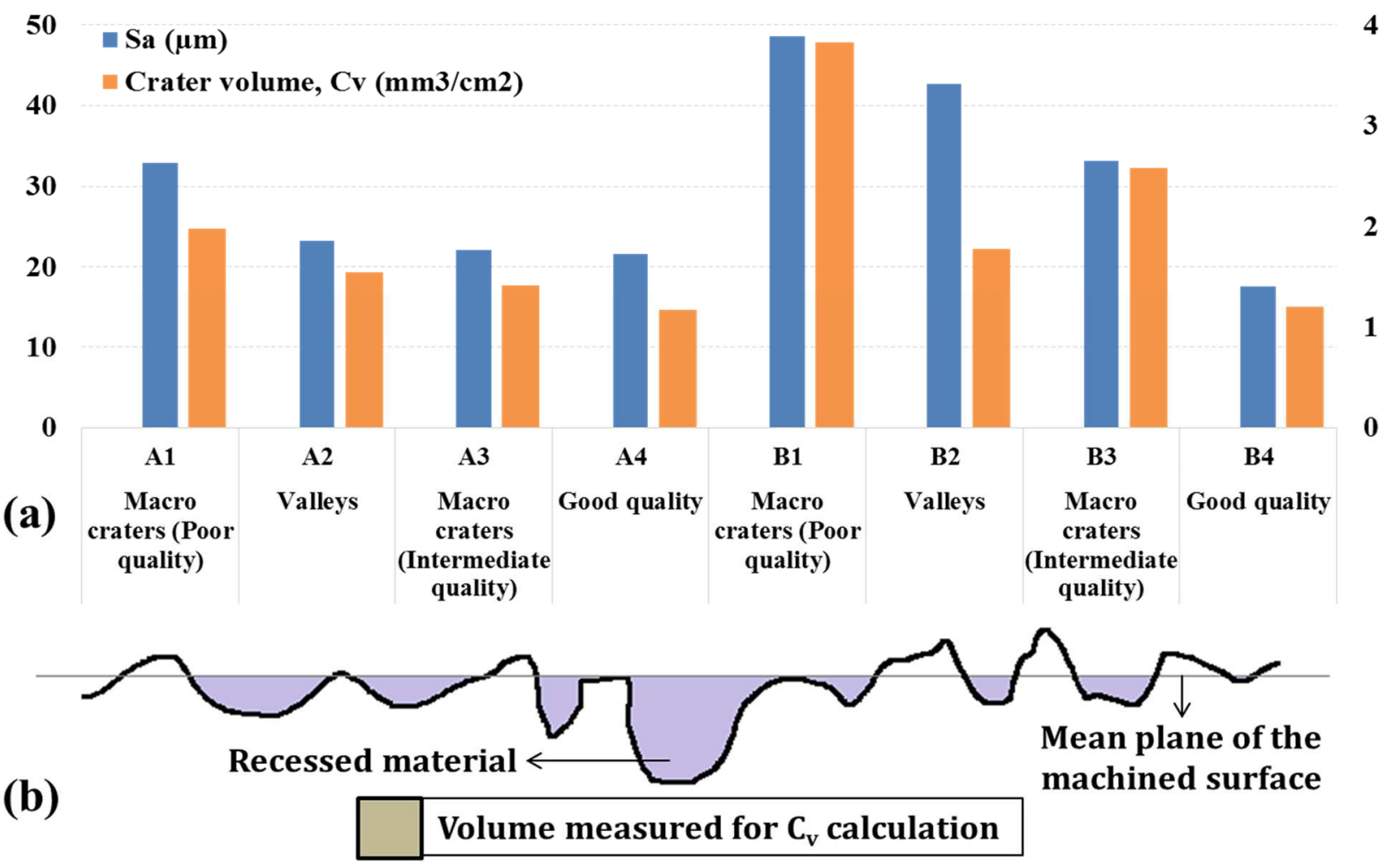

Fig. 8. 3D Surface characterization (a)3D surface characterization $\left(S_{a}\right) \&$ damage quantification $\left(\mathrm{C}_{\mathrm{V}}\right)$ of milled specimens. (b) Schematic showing the approach for crater volume measurement.

\subsection{Static tensile tests}

Static tensile tests were performed to identify the maximum tensile strength of the different machined specimens in order to design the tension-tension fatigue tests. The typical stress-strain curves obtained for group B specimens is shown in the Fig 9a. Even though the specimens have different levels of damage, it can be noticed that tensile behavior of specimens are almost similar. However, when comparing the maximum tensile strength $\left(\sigma_{\mathrm{uts}}\right)$ of both the groups of specimens A (1 ply milled) and B (2 plies milled) with different levels of damage (Fig. 9b), it can be seen that the specimens considered as good quality ( $\mathrm{Sp}$ - A4 and Sp - B4) exhibit the highest tensile strength. It is reasonable that a specimen with least damage demonstrates superior mechanical behavior. However, the values fall in such a close range that it is difficult to determine exact cause of variation in the tensile strength. In addition, when the tensile strength 
values are populated against surface roughness there is no clarity regarding the influence of machined surface quality, as all values are closely populated (shown by an enclosed circle in Fig. 10a). This can be considered as random distribution of the tensile strength values in function of the roughness parameter. However, the Fig. 10b shows a clear reduction in the tensile strength with increase of the crater volume, hinting that machining damage in fact has an adverse effect on the mechanical behavior. These results suggest that characterization of surface quality based on surface roughness may be misleading. Similar results showing erratic evolution of mechanical behavior as a function of surface roughness have been observed by some researchers $[8,36]$. The closely populated tensile strength values and the fact that tensile loading is seldom representative of the real service conditions, it is proposed that further tests are necessary to ascertain the influence of machining on the mechanical behavior. For this reason, additional tension-tension fatigue tests are performed whose protocol design is based on the obtained tensile strength values.
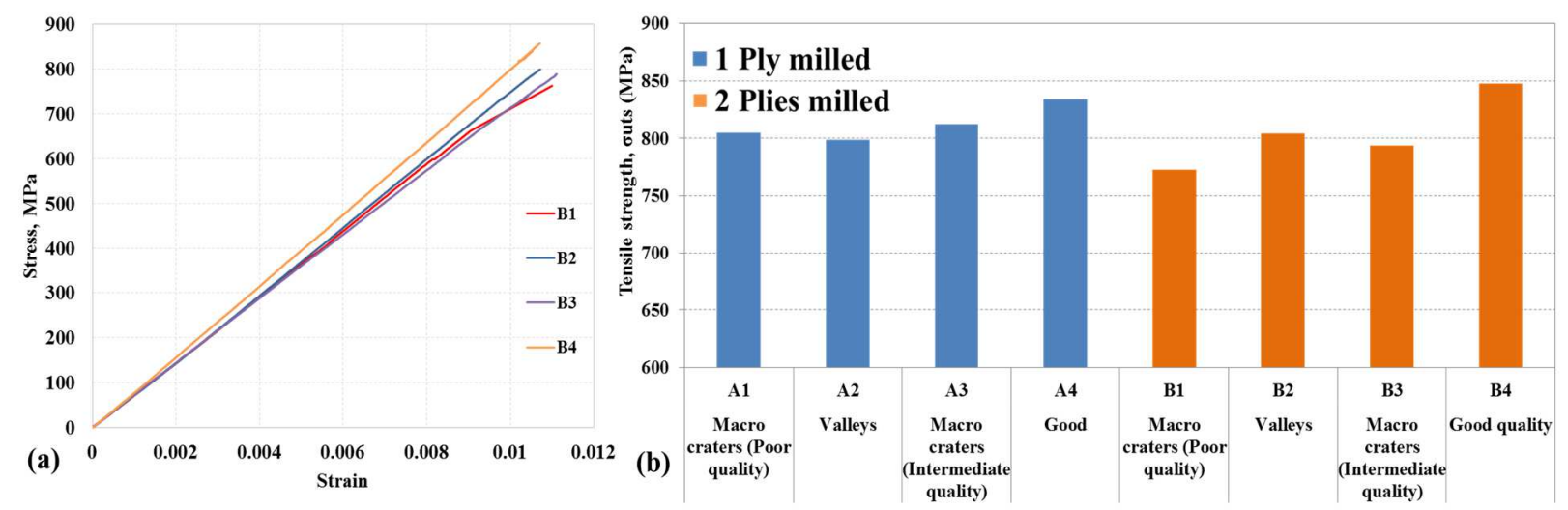

Fig. 9. (a) Typical stress-strain curves of group B specimens under static tensile loading. (b) Static tensile strength, $\sigma_{\text {uts }}(\mathrm{MPa})$ of different machined specimens.
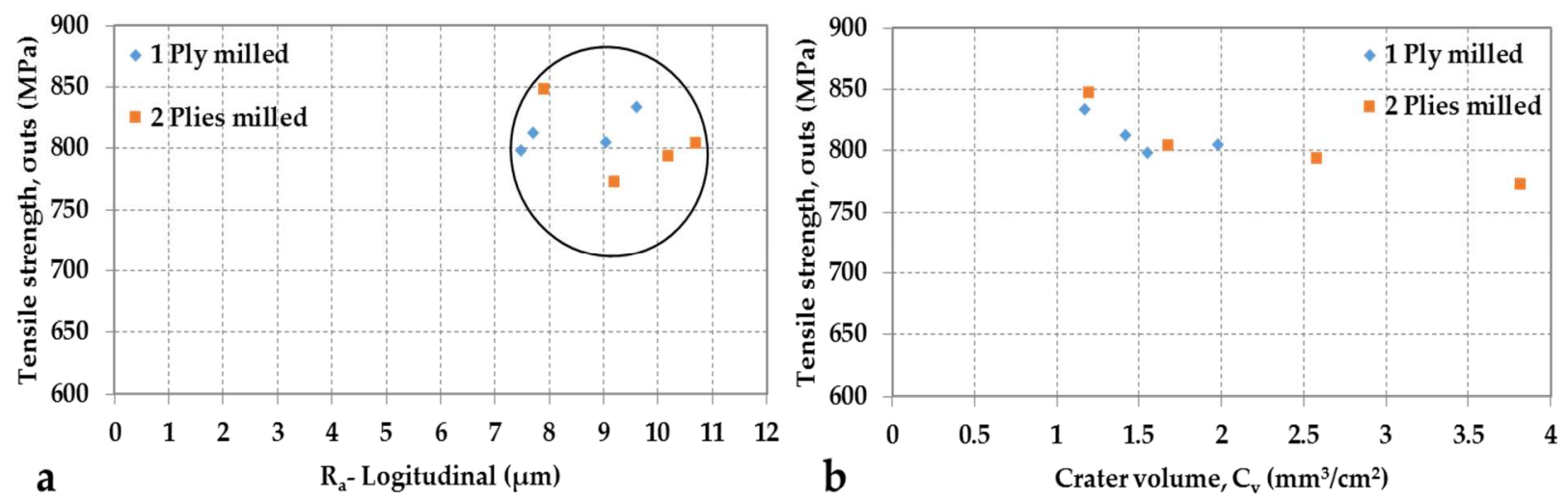

Fig. 10. Static tensile strength, $\sigma_{\text {uts }}(\mathrm{MPa})$ of different machined specimens vs. (a) Surface roughness - $\mathrm{R}_{\mathrm{a}}$-Longitudinal and (b) Crater volume $\left(\mathrm{C}_{\mathrm{v}}\right)$ 


\subsection{Fatigue tests}

The specimen failure under fatigue loading occurs due to progressive accumulation of damage, leading to final failure. The progression of damage is studied using acoustic emission energy and heat dissipation data (Thermography). During loading, specimen damage occurs by matrix cracks, fiber breaks and crack propagation. These phenomena are accompanied by emission of acoustic waves (acoustic emission (AE) energy) which is measured using acoustic emission transducers. Higher the number of events like matrix cracks, fiber breaks and crack propagation higher is the AE energy released. Similarly, these events also give rise to heat dissipation which increases the specimen temperature. In addition to this, heat is also generated due to the friction between the broken fibers or opened crack surfaces leading to local temperature rise observed at the proximity of the damage sites. Infra-red thermography is utilized in this study to measure these temperature evolutions on the external surface of the specimen during fatigue loading.

The evolution of the rise in the specimen temperature at the end of each load block is presented as a function of the maximum cycle stress applied in each load block for group A and group B specimens in the Fig. 11a and Fig. 11b respectively. This chart corresponds to one of the 3 specimens tested for each machining quality and other specimens follow similar trend. From Fig. 11a it is clearly noticed that maximum rise in temperature as a function of the applied stresses is attributed to the Specimen A1 which is mainly characterized by extensive macro crater damages. Conversely, specimen A4 which is characterized by good machining quality (Low $\mathrm{C}_{\mathrm{v}}$ ) depicts lowest temperature rise. It is to be noted that poor quality specimens contain broken and bare fibers, micro and macro craters which advances the temperature rise due to friction (at the damage interface), in comparison with good quality specimens. In addition, when group B specimens (Fig. 11b) are considered; the evolution of temperature rise against maximum cycle stress is not distinct as in group A specimens. However, poor quality specimens B1 and B2 depict highest temperature rise. It is important to note that, group B specimens are milled using higher jet pressure in order to remove 2 plies in one pass. However, if we refer to our previous work, machining with higher jet pressure augments the creation of micro craters, micro cracks and broken fibers which are randomly distributed on the specimen surface (cf. Fig. 7). In fact, these damages progress the crack growth even at low loads, leading to friction between opened crack surfaces during loading. This friction causes additional source of heat generation and hence local rise in temperature in the proximity of damage caused by machining is seen. This local rise in 
temperature is different from overall temperature rise in the specimen due heat dissipation caused by fatigue loading. As the machined damage is spread all over the specimen surface, it is difficult to distinguish between the temperature rise due to fatigue loading damage (matrix cracking and fiber fracture) and the temperature generated by the friction phenomenon due to the pre-existing damage due to machining, hence this anomaly in results of group B specimens.
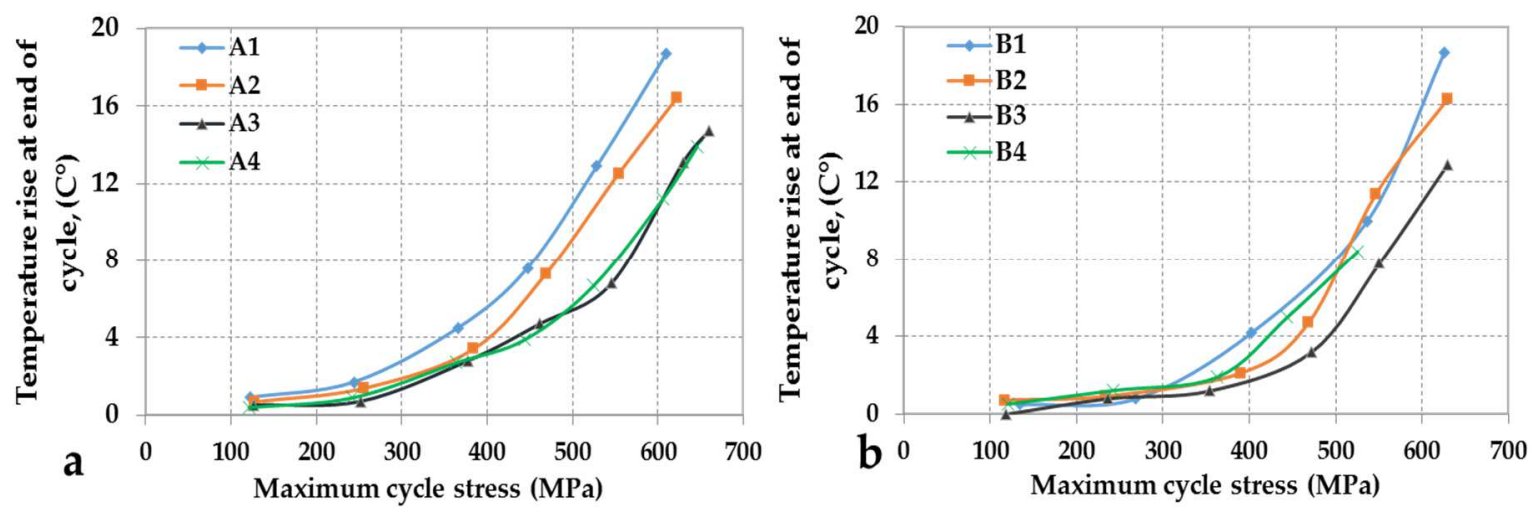

Fig. 11. Evolution of the rise in specimen temperature at the end of each load block as a function of the maximum stress applied. Machined specimens where (a): one ply is removed and (b): two plies are removed.

It is important to mention that; the temperature rise due to heat dissipation has been used by several researchers for quicker estimation of the endurance limit by temperature stabilization method without the use of time consuming Whöler or S-N curves approach. Initially, this temperature stabilization method was used for metallic materials (Luong et al. [41] and La Rosa et al. [42]), however several studies $[8,39,40,43]$ have successfully adopted this method for composite materials and produced effective results. In this method, the mean rise in specimen temperature at the end of each loading block (10000 cycles) is plotted against the maximum cycle stress applied in each load block. The obtained points can be fitted into 2 straight lines with different slopes which intersect at a point depicting the endurance limit. However, to get these plots, the rise in temperature at the loading level close to failure, where macro fracture occurs is not considered. The variation in temperature at these load levels is not representative of the overall specimen temperature and it is a local temperature rise specific to the type of damage in the specimen. The Fig. 12 shows the endurance limit of all the machined specimens, the endurance limits here represent the average of 3 fatigue tests conducted for each specimen to have good repeatability of the results. The positive and negative error bars represent the maximum and minimum endurance limit value obtained for 3 tests respectively. It is clear from 
the Fig. 12 that, the endurance limit is strongly influenced by the size and nature of the machining damage.

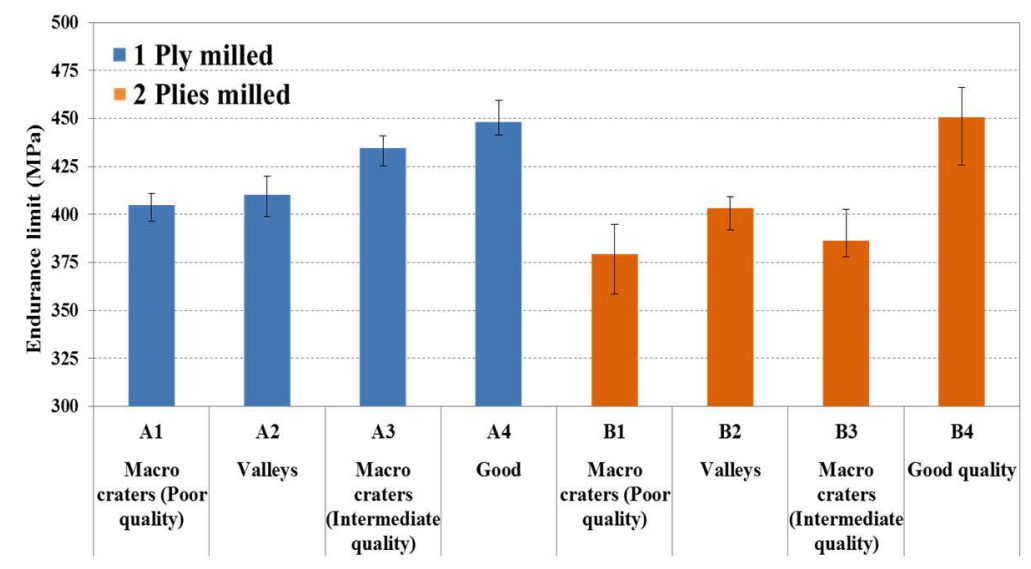

Fig. 12. Influence of the machining quality on the endurance limit (MPa) of the different specimens.

In order to understand the influence of machined surface quality and damage on fatigue behavior, the endurance limit values of the specimens are plotted against surface roughness $\left(\mathrm{R}_{\mathrm{a}}\right.$ L) and crater volume $\left(\mathrm{C}_{\mathrm{v}}\right)$ as shown in the Fig. 13a and Fig. 13b respectively. As discussed previously for tensile strength values, qualification of machining quality using the surface roughness criteria is inappropriate for composites. Similar results are seen from Fig. 13a for endurance limit, where all the values are closely populated (enclosed circle) even though they have huge difference in machining damage levels. However, when plotted against crater volume " $\mathrm{C}_{\mathrm{v}}$ " (Fig. 13b) a decreasing trend of endurance limit is seen against increasing crater volume (machining damage). Also, from Fig. 13b it can be observed that group B specimens have longer error bars than group A specimens. For instance, when we consider the endurance limit values in Fig. 13b emphasized by an enclosed dotted rectangle, it is seen that for almost the same value of " $\mathrm{C}_{\mathrm{v}}$ " the group A and B specimens have a same endurance limit. However, group B specimens differ by longer length of error bar (maximum and minimum endurance limit value). This deviation is due to the randomness in presence of micro craters, micro cracks and embedded abrasive particles in specimens machined with high jet pressure. In addition, the measurement of " $\mathrm{C}_{\mathrm{v}}$ " includes macro and micro craters but ignores the presence of micro cracks and abrasive embedment. This means that two specimens with same $C_{v}$ may contain different levels of micro cracks and embedded abrasives which encourages the deviation in the values of endurance limit. 

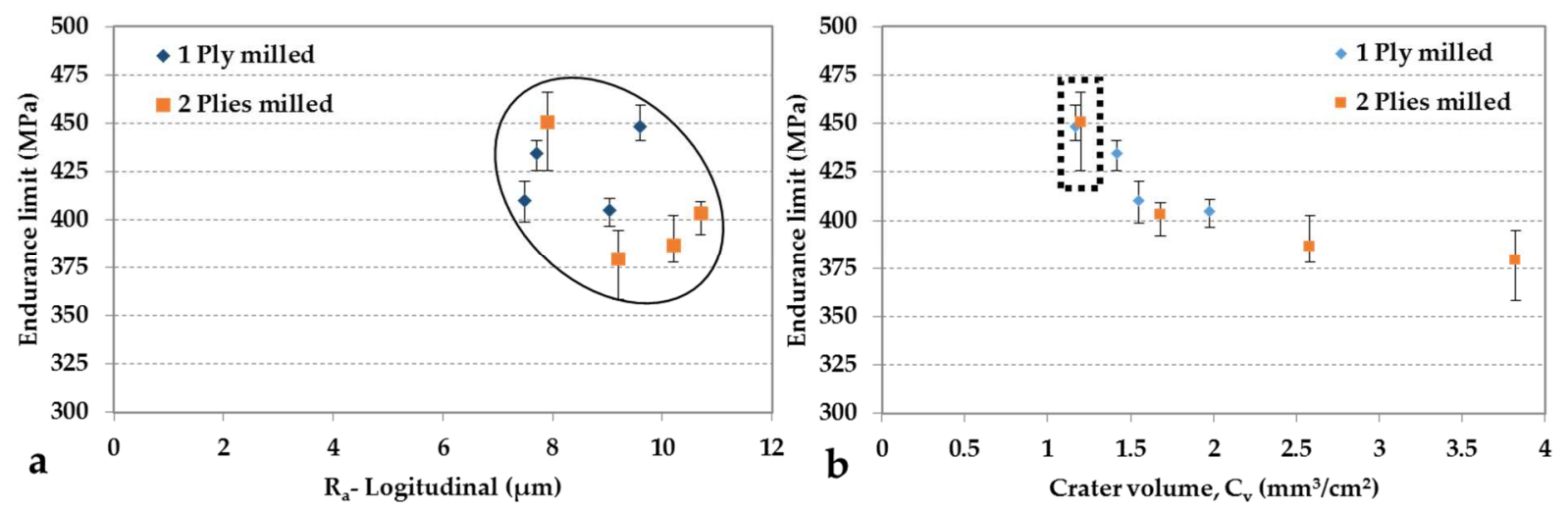

Fig. 13. Variation of the endurance limit (MPa) of different machined specimens vs. the surface characterization criteria. (a): Surface roughness - $\mathrm{R}_{\mathrm{a}}$-Longitudinal used as criterion of characterization and (b) Crater volume $-\mathrm{C}_{\mathrm{v}}$ used as criterion of characterization.

In order to better understand the damage mechanisms occurring during fatigue loading with respect to the machining quality, the maximum cycle stress of each load block is plotted against the cumulative acoustic emission (AE) energy at the end of each loading block for different group A and B specimens (Fig. 14a and Fig. 14b). From Fig. 14a it is seen that AE energy dissipated is almost similar for all specimens of the group A up to maximum cycle stress of $400 \mathrm{MPa}$. This increase in acoustic energy at low stress levels is due to the propagation of preexisting micro cracks and matrix cracking [44]. However, at higher stress levels the AE energy rapidly increases for poor quality specimens (e.g. specimen A1) in comparison with good quality specimens (e.g. specimen A4). The presence of micro and macro craters, valleys and broken fibers in poor quality specimens advance the fiber breakage and crack propagation giving rise to dissipation of high energy acoustic waves and hence, the rapid rise in $\mathrm{AE}$ emission energy for poor quality specimens. This also means that the damage accumulation in poor quality specimens advances at a higher rate in comparison with good quality specimens. However, from Fig. 14b showing group B specimens, it is seen that the initial rate of AE energy dissipation is different for each specimen unlike group A specimens. The group B specimens are machined at a higher jet pressure than group A specimens, hence the presence of micro craters, micro cracks and broken fibers is predominant. Therefore, the dissipation of AE energy is higher in specimens with more micro cracks/craters compared to specimens with less pre-existing micro cracks/craters. In addition, it is also seen that majority of the fatigue damage in the group A specimens occur at higher loads (applied cycle stress > $400 \mathrm{MPa}$ ) where as in group B specimens fatigue damage starts at a very early stage (applied cycle stress $>150 \mathrm{MPa}$ ). This is also proved by the fact that 
the accumulated AE energy before the final failure is very high for group B specimens indicating that specimen damage starts from an early stage. For the validation of these scenarios of damage (under fatigue loading), the postmortem observation of the specimens has been conducted using the X-ray tomography and the SEM techniques.
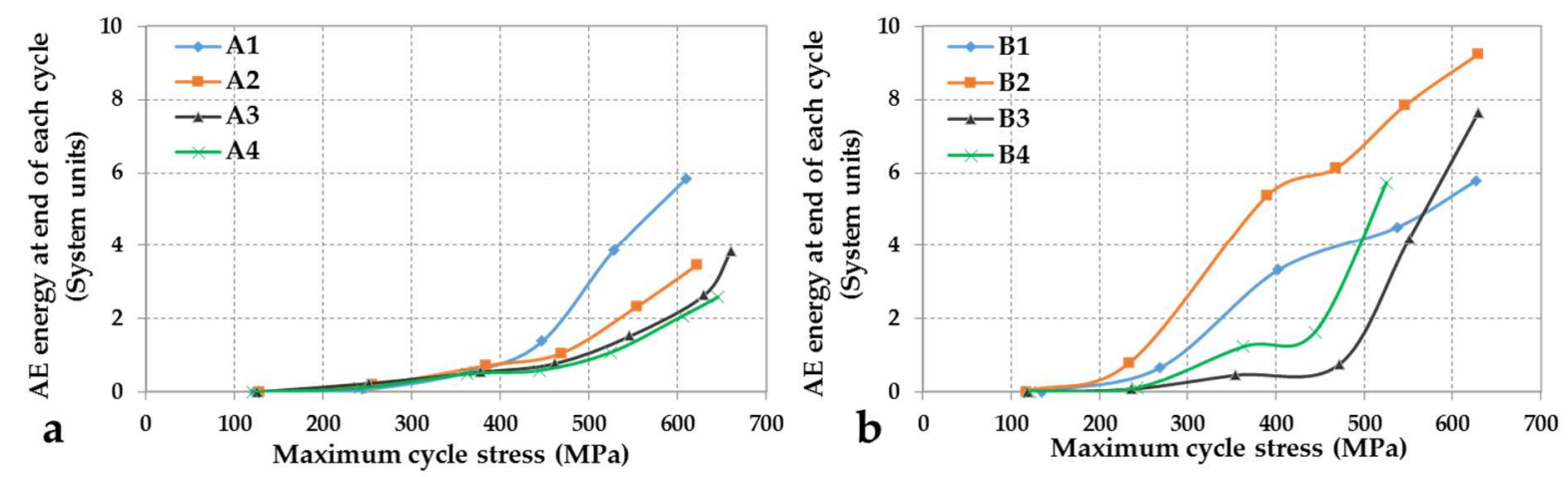

Fig. 14. Evolution of the cumulative AE energy of different specimens at the end of each load block as a function of the maximum stress applied. Machined specimens where (a): one ply is removed and (b): two plies are removed.

\subsection{Mechanism of failure and postmortem observation}

The X-Ray tomography imaging was conducted in order to study failure progression and mechanism after loading the specimen for 10000 cycles at maximum cycle load of $25 \% \mathrm{~F}_{\mathrm{uts}}$,

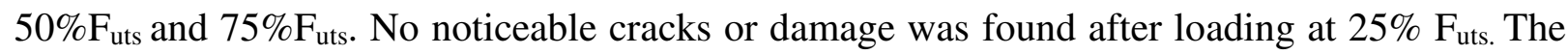
tomography images taken after loading at $50 \% \mathrm{Futs}_{\mathrm{u}}$ revealed the presence of microscopic cracks (0.2-0.4 $\mathrm{mm}$ in length).

The tomography images taken after $75 \% \mathrm{~F}_{\mathrm{uts}}$ reveal the presence of cracks $(>0.4 \mathrm{~mm}$ in length) and debonded fiber-matrix bunches on the machined surface. The Fig. 15 shows the images depicting the cracks (Fig. 15, Zone 1 and 2) and debonded fiber-matrix bunches (Fig. 15, Zone 3). All the cracks and debonding fiber bunches observed were originating from the base/tips of the micro craters formed due to machining. However, in the specimens with the presence of macro craters (Specimen B1), the cracks were seen originating from the walls of the macro crater (Fig. 15a, Y-Slices, Zone 2). The debonding of the fiber bunches (Fig. 15, Zone 3) was observed for both good quality (A4) and poor quality (B1) specimens. Based on these results, the failure mechanism of AWJ machined CFRP specimens under fatigue loading can be expected to occur in 4 steps. (a) Formation of micro cracks in matrix. (b) Crack opening and bunches fiber-matrix debonding from the base of the craters (Fig. 15, Zones 1, 2 and 3). (c) Growth of the cracks and 
fiber-matrix debonding and formation of a network of cracks underneath the machined surface (Fig. 15b, X-Slices, Zone 4). (d) Complete failure of the outermost plies causing rapid reduction in stiffness and eventually leading to complete failure of the specimen.

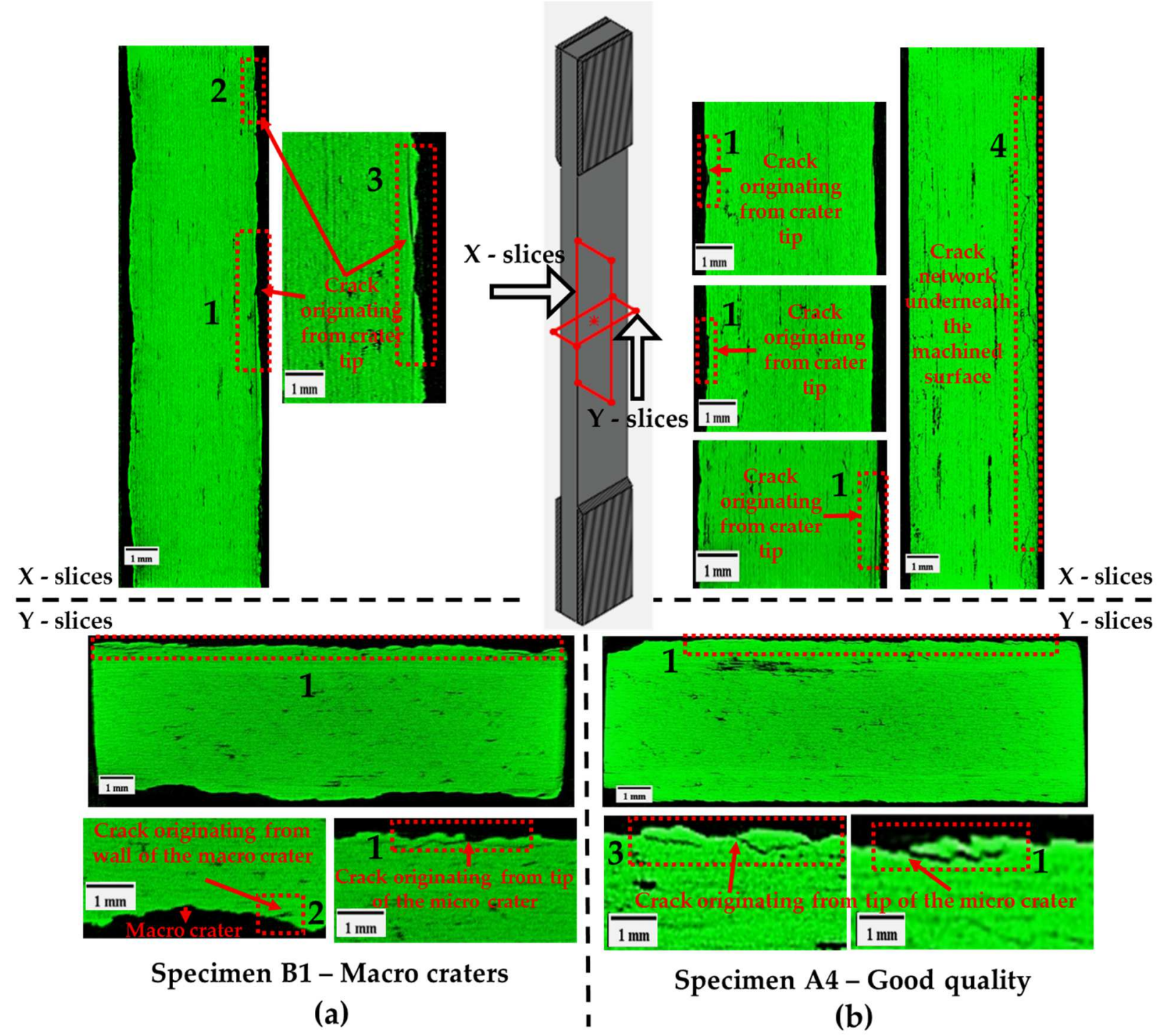

Fig. 15. X-Ray tomography images showing internal cracks formed after fatigue loading cycle of $75 \% \mathrm{~F}_{\text {uts. }}$ (a) $\mathrm{X}$ and $\mathrm{Y}$ slice images of specimen $\mathrm{B} 1$ characterized by macro craters, (b) $\mathrm{X}$ and Y slice images of specimen A4 with best quality of machining. Where (1) shows cracks originating from micro craters, (2) shows cracks originating from walls of macro craters, (3) shows bunches of fiber-matrix debonding and (4) shows network of cracks underneath the machined surface.

The specimens were analyzed using SEM after loading at $75 \% \mathrm{~F}_{\text {uts. }}$. The SEM observations are presented in the Fig. 16. The presence of cracks and debonding of fiber-matrix 
bunches can be noticed clearly. Micro cracks in matrix and fiber (Fig. 16a) is seen all over the machined surface. It was predicted from the X-ray tomography images that the cracks and debonding of fiber-matrix bunches originated from the base and edges of the micro and macro craters. This phenomenon is clearly seen in the SEM images (Fig. 16b and Fig. 16c). Here, it can be observed from Fig. 16c that the cracks and damage in specimen machined with low jet pressure of $80 \mathrm{MPa}$ is more severe in comparison with the specimen machined with high jet pressure of $140 \mathrm{MPa}$ (cf. Fig. 16b). It was ascertained from SEM analysis of the machined specimens (Section 3.1) that the occurrence of micro craters in specimens machined with high jet pressure was prevalent, which was also confirmed from the high $\mathrm{C}_{\mathrm{v}}$ value. Therefore, it can be said that higher jet pressure leads to augmented occurrence of the micro craters, which in turn leads to formation of severe cracks in the material during fatigue loading. In addition, Debonding and fiber cracks were seen originating from embedded abrasive particles in the machined surface (Fig. 16d). As the cracks grow in length, several cracks join to debond a bunch of fiber-matrix from the machined surface leading to failure of the outer ply (Fig. 16e) and eventually the whole specimen.

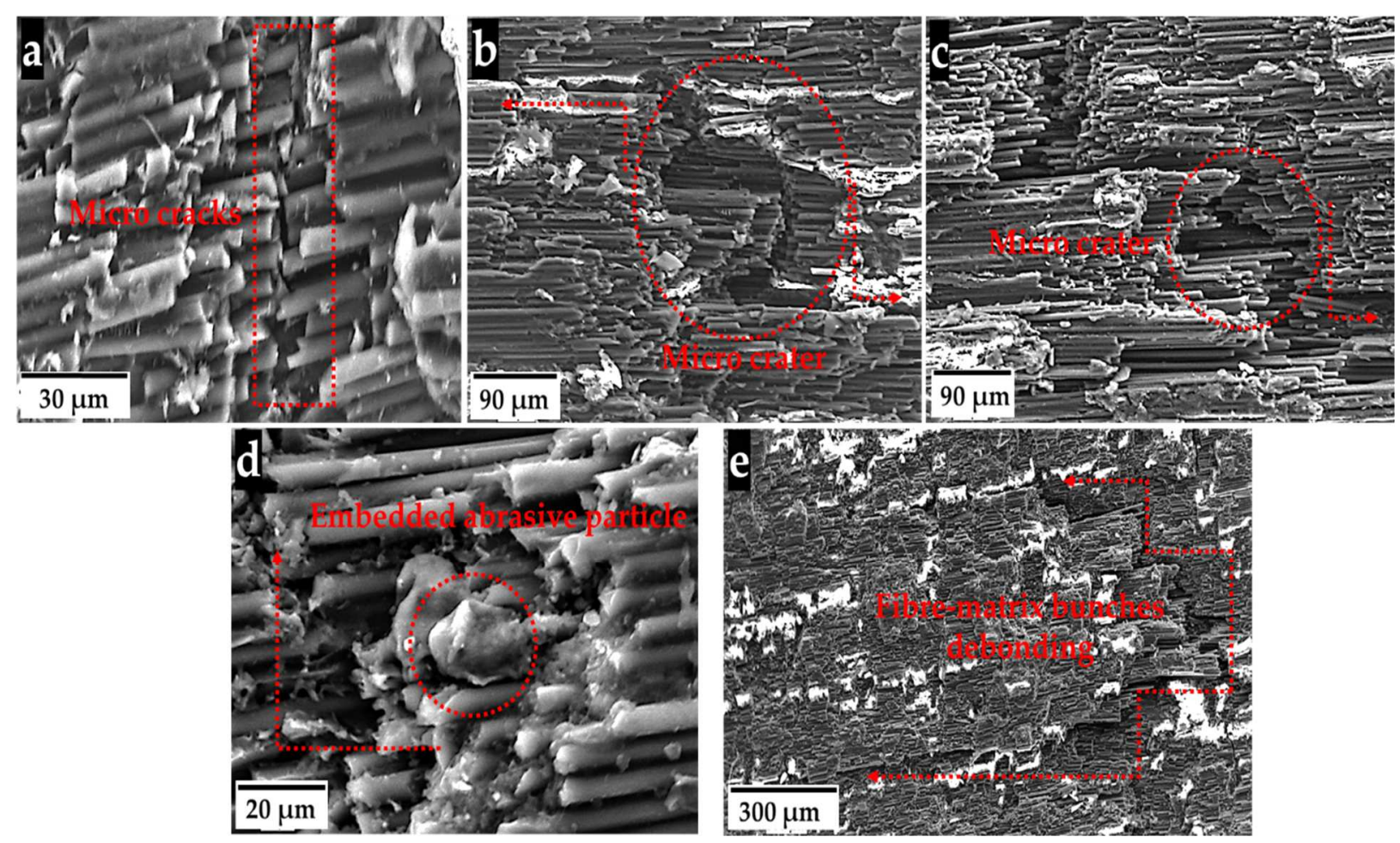

Fig. 16. SEM micrographs showing cracks formed after fatigue loading cycle of $75 \% \mathrm{Futs}_{\text {. }}$ (a) Micro cracks formed all over the machined surface. (b) Cracks originating from micro crater of a specimen machined with $80 \mathrm{MPa}$ jet pressure. (c) Cracks originating from micro crater of a 
specimen machined with $140 \mathrm{MPa}$ jet pressure. (d) Cracks originating from embedded abrasive particle. (e) Network of surface cracks connect to debond fiber-matrix bunches from the machined surface.

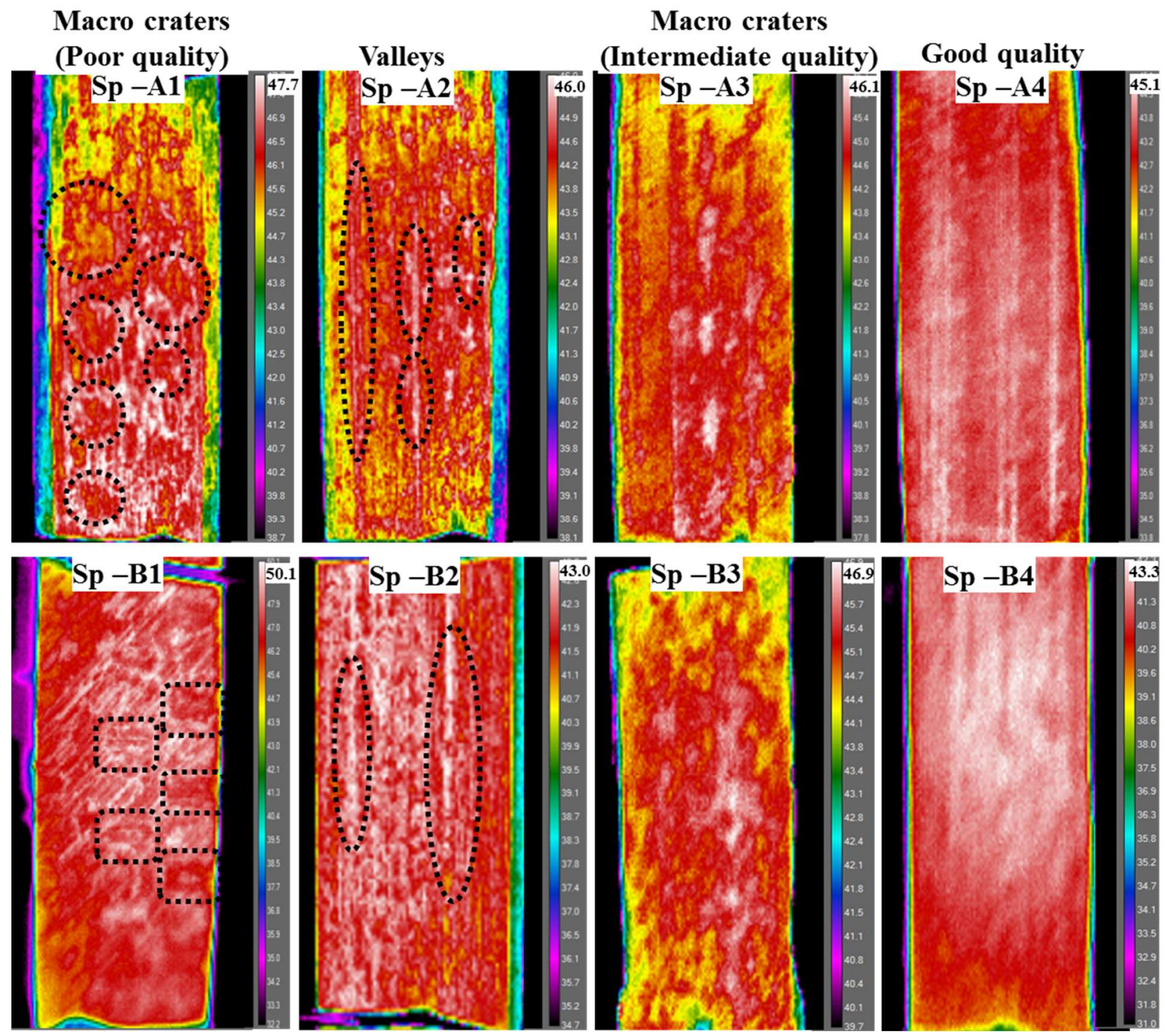

Fig. 17. Thermal cartographies of different specimens undergoing fatigue testing according to the protocol described in section 2.4. Shortly before the failure; Specimens A1-A4 in first row and Specimen B1-B4 in the second row.

The fact that the cracks form and propagate from the edges of micro craters and the walls of macro craters, can be confirmed from the thermal cartographies (cf. Fig. 17) obtain just before the final failure of the specimens undergoing the tension-tension fatigue tests according to the 
protocol described in the section 2.4 (Fig. 4). If fact, it is seen from the Fig. 17, that for the specimens Sp-A1 and B1 the zones with highest temperature are situated around the macro craters (enclosed in dotted lines). Similarly, for the specimens Sp-A2 and B2 characterized by valleys, the highest temperature is seen around the valley defects. This means that, there are cracks formed around the vicinity of the craters and valleys (as predicted from X-Ray tomography), which create excessive heat dissipation due friction between the surfaces leading to temperature higher than the average specimen temperature. It is to be noted that, the average specimen temperature rise is due to the heat dissipation during fatigue loading, whereas these local high temperature zones are due to the action of friction between cracked surfaces and debonded fiber-matrix bunches present close to the defects formed due to machining. In comparison, when specimens Sp-A3, A4, B3 and B4 are considered the temperature distribution is homogenous on the specimen surface, which means that the rise in temperature is fundamentally because of the damage generation as a result of fatigue loading rather than friction between the cracked surfaces. This means that, specimens characterized with minimum machining defects (craters) perform better under fatigue loading, i.e. a specimen with low $\mathrm{C}_{\mathrm{v}}$ (fewer craters) will exhibit a superior mechanical behavior. Hence, in practice machining parameters should be optimized to for low $\mathrm{C}_{\mathrm{V}}$ (which indicates a reduced presence of defects).

\section{Conclusion}

A study of damage and surface characteristics induced in CFRP laminates by AWJ milling and its influence on the fatigue behavior of machined specimens has been presented in this article. AWJ milling parameters (jet pressure (MPa), scan step $(\mathrm{mm})$, stand-off distance $(\mathrm{mm})$ and jet traverse speed $(\mathrm{m} / \mathrm{min})$ ) were varied to obtain specimens with different surface quality and damage levels. To study the influence of AWJ milling on the tensile and fatigue behavior, the ultimate tensile strength and endurance limit of the specimens were correlated to the surface quality and damage level. Apart from quantifying the machined surface quality, using the traditional criterion $\left(R_{a}\right)$, the surface quality was also characterized as $C_{v}$ which quantifies the damage level (crater volume size). The following critical conclusions can be drawn from this study:

- Combination of various AWJ milling parameters at different levels create a surface with diverse damage forms like micro and macro craters, broken and bare fibers, embedded abrasive particles, fiber-matrix debonding and ridges-valleys. For a precise and practical 
correlation of machining quality with the mechanical behavior, the damage in the form of craters was quantified by introducing a new parameter termed crater volume $\left(\mathrm{C}_{\mathrm{v}}\right)$.

- The presence of the mentioned damages adversely impacted the mechanical performance of the machined composite during the static and fatigue loading. In fact, the static tensile tests revealed that the tensile strength of the machined specimens varied with damage levels $\left(c_{v}\right)$. However, due to the low variation $(807 \mathrm{MPa} \pm 5 \%$ ) in the tensile strength values of all the specimens, it would be questionable to attribute these variations to the machining quality alone as it may also arise due to the variability in the mechanical properties due to the process of manufacturing.

- The fatigue tests reveal that, the endurance limit of the machined specimens showed high variation (413 $\mathrm{MPa} \pm 14 \%$ ) clearly demonstrating the unfavorable effect of machining quality on the mechanical properties induced.

- A superior fatigue behavior is exhibited by specimens machined at low jet pressure (1 ply removed). High material removal rates can be achieved at high jet pressure at the expense of reliable mechanical behavior.

- The failure mechanisms of machined specimens under fatigue loading occurs in four stages: (i) formation of micro cracks in matrix, (ii) crack opening and debonding of fiber-matrix bundles, (iii) growth of the cracks and fiber-matrix debonding and formation of a network of cracks underneath the machined surface and finally (iv) failure of the outermost plies causing rapid reduction in stiffness leading to complete failure of the specimen.

- Correlation of the mechanical properties (maximum failure stress and endurance limit) with the newly proposed quality criterion $\left(\mathrm{C}_{\mathrm{V}}\right)$ has cleared the uncertainty that was faced due to correlation of mechanical properties with surface roughness $\left(\mathrm{R}_{\mathrm{a}}\right)$ and proved to be more realistic in the case of CFRP composites.

\section{References}

[1] Ahmad J. Machining of Polymer Composites. Boston, MA: Springer US; 2009.

[2] Komanduri R. MACHINING OF FIBER-REINFORCED COMPOSITES. Mach Sci Technol 1997;1:113-52.

[3] Teti R. Machining of Composite Materials. CIRP Ann 2002;51:611-34.

[4] Katnam KB, Da Silva LFM, Young TM. Bonded repair of composite aircraft structures: 
A review of scientific challenges and opportunities. Prog Aerosp Sci 2013;61:26-42.

[5] Collombet F, Grunevald Y-H, Crouzeix L, Douchin B, Zitoune R, Davila Y, et al. Repairing composites. Adv. Compos. Manuf. Process Des., Elsevier; 2015, p. 197-227.

[6] Haddad M, Zitoune R, Eyma F, Castanie B. Study of the surface defects and dust generated during trimming of CFRP: Influence of tool geometry, machining parameters and cutting speed range. Compos Part A Appl Sci Manuf 2014;66:142-54.

[7] Hejjaji A, Singh D, Kubher S, Kalyanasundaram D, Gururaja S. Machining damage in FRPs: Laser versus conventional drilling. Compos Part A Appl Sci Manuf 2016;82:4252.

[8] Haddad M, Zitoune R, Bougherara H, Eyma F, Castanié B. Study of trimming damages of CFRP structures in function of the machining processes and their impact on the mechanical behavior. Compos Part B Eng 2014;57:136-43.

[9] Davim JP, Reis P. Damage and dimensional precision on milling carbon fiber-reinforced plastics using design experiments. J Mater Process Technol 2005;160:160-7.

[10] Nguyen-Dinh N, Hejjaji A, Zitoune R, Bouvet C, Crouzeix L. Machining of FRP Composites: Surface Quality, Damage, and Material Integrity: Critical Review and Analysis. In: Sidhu SS, Bains PS, Zitoune R, Yazdani M, editors. Futur. Compos. Mater. Horizons From Nat. to Nanomater., Springer, Singapore; 2018, p. 1-35.

[11] Nguyen-Dinh N, Zitoune R, Bouvet C, Le Roux S. Experimental study of dust emission during trimming of CFRP structures with pcd tool. ECCM 2018 - Proceeding 18th Eur. Conf. Compos. Mater., Athens: 2018.

[12] Walter J, Hustedt M, Staehr R, Kaierle S, Jaeschke P, Suttmann O, et al. Laser Cutting of Carbon Fiber Reinforced Plastics - Investigation of Hazardous Process Emissions. Phys Procedia 2014.

[13] Sheikh-Ahmad JY. Hole Quality and Damage in Drilling Carbon/Epoxy Composites by Electrical Discharge Machining. Mater Manuf Process 2016;31:941-50.

[14] Ramulu M, Arola D. The influence of abrasive waterjet cutting conditions on the surface 
quality of graphite/epoxy laminates. Int J Mach Tools Manuf 1994;34:295-313

[15] Hejjaji A, Zitoune R, Crouzeix L, Collombet F, Le Roux S. Impact of the abrasive water jet milling process on the damage and surface characteristics of CFRP composite. ECCM 2016 - Proceeding 17th Eur. Conf. Compos. Mater., Munich: 2016.

[16] Hejjaji A, Zitoune R, Crouzeix L, Roux S Le, Collombet F. Surface and machining induced damage characterization of abrasive water jet milled carbon/epoxy composite specimens and their impact on tensile behavior. Wear 2017;376-377:1356-64.

[17] Schwartzentruber J, Papini M, Spelt JK. Characterizing and modelling delamination of carbon-fiber epoxy laminates during abrasive waterjet cutting. Compos Part A Appl Sci Manuf 2018;112:299-314.

[18] Wang J. A machinability study of polymer matrix composites using abrasive waterjet cutting technology. J Mater Process Technol 1999;94:30-5.

[19] Momber AW, Kovacevic R. Principles of Abrasive Water Jet Machining. London: Springer London; 1998.

[20] Ramulu M, Colligan K. Edge finishing and delamination effects induced during abrasive waterjet machining on the compression strength of a graphite/epoxy composite. Am Soc Mech Eng Mater Div MD 2005:173-9.

[21] Paul S, Hoogstrate AM, Van Luttervelt CA, Kals HJJ. An experimental investigation of rectangular pocket milling with abrasive water jet. J Mater Process Technol 1998.

[22] Fowler G, Shipway PH, Pashby IR. A technical note on grit embedment following abrasive water-jet milling of a titanium alloy. J Mater Process Technol 2005.

[23] Shipway PH, Fowler G, Pashby IR. Characteristics of the surface of a titanium alloy following milling with abrasive waterjets. Wear 2005;258:123-32.

[24] Hashish M. An Investigation of Milling With Abrasive-Waterjets. J Eng Ind 1989.

[25] Srinivasu DS, Axinte DA. Mask-Less Pocket Milling of Composites by Abrasive Waterjets: An Experimental Investigation. J Manuf Sci Eng 2014. 
[26] Srinivasu DS, Axinte DA. Surface integrity analysis of plain waterjet milled advanced engineering composite materials. Procedia CIRP, 2014.

[27] Finnie GLS and I. The Mechanism of Material Removal in the Erosive Cutting of Brittle Materials. J Eng Ind 1966.

[28] Arola D, Ramulu M. A Study of Kerf Characteristics in Abrasive Waterjet Machining of Graphite/Epoxy Composite. J Eng Mater Technol 1996;118:256-65.

[29] Arola D, Ramulu M. Mechanisms of Material Removal in Abrasive Waterjet Machining of Common Aerospace Materials. In: hashish M, editor. Proc. 7th Am. Water Jet Conf., Seattle: Water Jet Technology Association; 1993, p. 43-64.

[30] Ramulu M, Arola D. Water jet and abrasive water jet cutting of unidirectional graphite/epoxy composite. Composites 1993;24:299-308.

[31] Haddad M, Zitoune R, Eyma F, Castanié B. Influence of Machining Process and Machining Induced Surface Roughness on Mechanical Properties of Continuous Fiber Composites. Exp Mech 2015;55:519-28.

[32] Arola D, Ramula M. Machining-induced surface texture effects on the flexural properties of a graphite/epoxy laminate. Composites 1994;25:822-34.

[33] Arola D, Ramulu M. Net shape manufacturing and the performance of polymer composites under dynamic loads. Exp Mech 1997;37:379-85.

[34] Arola D, Ramulu M. Net-Shape Machining and the Process-Dependent Failure of FiberReinforced Plastics Under Static Loads. J Compos Technol Res 1998;20:210.

[35] Herzog D, Jaeschke P, Meier O, Haferkamp H. Investigations on the thermal effect caused by laser cutting with respect to static strength of CFRP. Int J Mach Tools Manuf 2008;48:1464-73.

[36] Ghidossi P, El Mansori M, Pierron F. Edge machining effects on the failure of polymer matrix composite coupons. Compos Part A Appl Sci Manuf 2004;35:989-99.

[37] Squires CA, Netting KH, Chambers AR. Understanding the factors affecting the compressive testing of unidirectional carbon fibre composites. Compos Part B Eng 
2007;38:481-7.

[38] Kalyanasundaram D, Gururaja S, Prabhune P, Singh D. Open hole fatigue testing of laser machined MD-CFRPs. Compos Part A Appl Sci Manuf 2018;111:33-41.

[39] Montesano J, Fawaz Z, Bougherara H. Use of infrared thermography to investigate the fatigue behavior of a carbon fiber reinforced polymer composite. Compos Struct 2013.

[40] Djabali A, Toubal L, Zitoune R, Rechak S. An experimental investigation of the mechanical behavior and damage of thick laminated carbon/epoxy composite. Compos Struct 2018;184:178-90.

[41] Luong MP. Fatigue limit evaluation of metals using an infrared thermographic technique. Mech Mater 1998;28:155-63.

[42] La Rosa G. Thermographic methodology for rapid determination of the fatigue limit of materials and mechanical components. Int J Fatigue 2000;22:65-73.

[43] Saleem M, Toubal L, Zitoune R, Bougherara H. Investigating the effect of machining processes on the mechanical behavior of composite plates with circular holes. Compos Part A Appl Sci Manuf 2013;55:169-77.

[44] Bourchak M, Farrow IR, Bond IP, Rowland CW, Menan F. Acoustic emission energy as a fatigue damage parameter for CFRP composites. Int J Fatigue 2007;29:457-70. 